\title{
Acetylcholine Controls GABA-, Glutamate-, and Glycine- Dependent Giant Depolarizing Potentials that Govern Spontaneous Motoneuron Activity at the Onset of Synaptogenesis in the Mouse Embryonic Spinal Cord
}

\author{
Antonny Czarnecki, ${ }^{1,2,3 *}$ Hervé Le Corronc, ${ }^{1,2,3,4 *}$ Chiara Rigato, ${ }^{1,2,3}$ Barbara Le Bras, ${ }^{1,2,3}$ François Couraud, ${ }^{1,2,3}$ \\ Anne-Laure Scain, ${ }^{1,2,3}$ Anne-Emilie Allain, ${ }^{5,6}$ Christine Mouffle, ${ }^{1,2,3}$ Erika Bullier, ${ }^{1,2,3}$ Jean-Marie Mangin, ${ }^{1,2,3}$ \\ Pascal Branchereau, ${ }^{5,6 *}$ and Pascal Legendre ${ }^{1,2,3 *}$ \\ ${ }^{1}$ Institut National de la Santé et de la Recherche Médicale, Unité Mixte de Recherche S1130, Université Pierre et Marie Curie, Paris, Ile de France, France, \\ ${ }^{2}$ Centre National de la Recherche Scientifique, Unité Mixte de Recherche 8246, Université Pierre et Marie Curie, Ile de France, France, ${ }^{3}$ Université Pierre et \\ Marie Curie UM CR18 Université Paris 06, Ile de France, France, ${ }^{4}$ Université d’Angers, 49000 Angers, France, ${ }^{5}$ Université de Bordeaux, Institut de \\ Neurosciences Cognitives et Intégratives d'Aquitaine, Unité Mixte de Recherche 5287, F-33000 Bordeaux, France, and ${ }^{6}$ Centre National de la Recherche \\ Scientifique, Institut de Neurosciences Cognitives et Intégratives d'Aquitaine, Unité Mixte de Recherche 5287, F-33000 Bordeaux, France
}

A remarkable feature of early neuronal networks is their endogenous ability to generate spontaneous rhythmic electrical activity independently of any external stimuli. In the mouse embryonic SC, this activity starts at an embryonic age of $\sim 12 \mathrm{~d}$ and is characterized by bursts of action potentials recurring every 2-3 min. Although these bursts have been extensively studied using extracellular recordings and are known to play an important role in motoneuron (MN) maturation, the mechanisms driving MN activity at the onset of synaptogenesis are still poorly understood. Because only cholinergic antagonists are known to abolish early spontaneous activity, it has long been assumed that spinal cord (SC) activity relies on a core network of MNs synchronized via direct cholinergic collaterals. Using a combination of whole-cell patch-clamp recordings and extracellular recordings in E12.5 isolated mouse SC preparations, we found that spontaneous $\mathrm{MN}$ activity is driven by recurrent giant depolarizing potentials. Our analysis reveals that these giant depolarizing potentials are mediated by the activation of GABA, glutamate, and glycine receptors. We did not detect direct nAChR activation evoked by ACh application on MNs, indicating that cholinergic inputs between MNs are not functional at this age. However, we obtained evidence that the cholinergic dependency of early SC activity reflects a presynaptic facilitation of GABA and glutamate synaptic release via nicotinic AChRs. Our study demonstrates that, even in its earliest form, the activity of spinal MNs relies on a refined poly-synaptic network and involves a tight presynaptic cholinergic regulation of both GABAergic and glutamatergic inputs.

Key words: embryo; giant depolarizing potential; motoneuron; mouse; spinal cord; synaptogenesis

\section{Introduction}

A remarkable feature of the developing CNS is its ability to generate spontaneous electrical activity independently of any exter-

\footnotetext{
Received June 24, 2013; revised March 2, 2014; accepted March 31, 2014.

Author contributions: A.C., H.L., P.B., and P.L. designed research; A.C., H.L., C.R., B.L., A.-L.S., A.-E.A., and P.B. performed research; C.M. and E.B. contributed unpublished reagents/analytic tools; A.C., H.L., F.C., J.-M.M., P.B., and P.L. analyzed data; A.C., H.L., J.-M.M., P.B., and P.L. wrote the paper.

This work was supported by AFM Grant 15436, Institut National de la Santé et de la Recherche Médicale, Centre National de la Recherche Scientifique. A.-L.S. was supported by Fondation pour la Recherche Médicale. C.R. was supported by Association Française contre les myopathies. We thank Dr. Jamilé Hazan and Dr. Richard Miles for valuable help and discussions and Gilles Courtand for colocalization analysis.

The authors declare no competing financial interests.

*A.C., H. L., P.B. and P.L. contributed equally to this work.

Correspondence should be addressed to either of the following: Dr. Pascal Legendre, Institut National de la Santé et de la Recherche Médicale Unité Mixte de Recherche S1130, Centre National de la Recherche Scientifique Unité Mixte de Recherche 8246, Université Pierre et Marie Curie, Bâtiment B, Etage 2, Boite postale 37, 7 quai Saint Bernard, 75005 Paris, France, E-mail: pascal.legendre@snv.jussieu.fr; or Pascal Branchereau, Institut de Neurosciences Cognitives et Intégratives d'Aquitaine, Université de Bordeaux et Centre National de la Recherche Scientifique Unité Mixte de Recherche 5287, Site Talence-Allée Geoffroy Saint-Hilaire Bât B2 4 ème étage Est, CS 50023, 33615 Pessac Cedex, E-mail: pascal.branchereau@u-bordeaux.fr.
}

nal stimuli. This early synchronized activity is characterized by bursts of action potentials occurring at low frequency (Allène and Cossart, 2010; Blankenship and Feller, 2010) and has been observed in various developing nervous structures, such as the retina, the cortex, the hippocampus, the cerebellum, the hindbrain, the forebrain, and the spinal cord (SC) (Landmesser and O’Donovan, 1984; Ben-Ari et al., 1989; Garaschuk et al., 1998, 2000; Gust et al., 2003; Corlew et al., 2004; Marder and Rehm, 2005; Myers et al., 2005; Gonzalez-Islas and Wenner, 2006; Hanson et al., 2008; Rockhill et al., 2009; Watt et al., 2009). Early synchronized activity plays important roles during the development of the CNS and contributes to the maturation of local neuronal networks (Moody and Bosma, 2005; Mohajerani and Cherubini, 2006; Spitzer, 2006). In the SC, this activity regulates motoneuron ( $\mathrm{MN}$ ) axon pathfinding and the development of the 
first functional neuronal networks (Hanson et al., 2008). A large variety of mechanisms underlying synchronized early electrical activity have been proposed depending on the developmental stage and the CNS area. These mechanisms include gap junctions between neurons, intrinsic voltage-dependent conductance (Allène and Cossart, 2010; Blankenship and Feller, 2010), nonvesicular paracrine release of neurotransmitters (Demarque et al., 2002; Scain et al., 2010), and synaptically driven slow depolarization, including glutamatergic early network oscillations in the developing cortex and GABAergic giant depolarizing potentials (GDPs) in the developing hippocampus and neocortex (Allène and Cossart, 2010). In the mouse embryonic SC, experiments based on extracellular recordings suggest that GABAergic and cholinergic synaptic transmission is important for the occurrence of bursts of action potential at the onset of electrical activity (embryonic age $12.5 \mathrm{~d}$; E12.5), whereas glutamatergic synaptic transmission is assumed to occur only at later embryonic stages (Branchereau et al., 2002; Hanson and Landmesser, 2003; Myers et al., 2005; Scain et al., 2010). However, the mechanisms controlling early MN activity have yet to be identified for the vast majority of them.

In the present study, based on multiple approaches, we have investigated the role of neurotransmitter release in driving $\mathrm{MN}$ activity at the onset of spontaneous activity in the embryonic lumbar mouse SC (E12.5). We found that MN activity occurs as recurrent GDPs. Although activation of the ACh receptor is necessary for the generation of SC activity, our analysis reveals that GDPs in MNs are mostly mediated by the activation of postsynaptic $\mathrm{GABA}_{\mathrm{A}}$, glycine, and glutamate receptors. Cholinergic inputs between MNs are unlikely to be functional at E12.5, as we did not detect any currents mediated by nicotinic cholinergic receptors (nAChRs) on MNs at this age. In addition, synaptic release of GABA and glutamate onto MNs strongly depends on the presynaptic activation of nAChRs. Our study thereby demonstrates that MN activity at the onset of synaptogenesis relies on interneuron (IN) activity and on a synaptic network involving cholinergic presynaptic regulation of GABA and glutamate release.

\section{Materials and Methods}

Isolated SC preparation. These experiments were performed in accordance with European Community guiding principles on the care and use of animals (86/609/CEE, CE Off J L358, December 18, 1986), the French decree 97/748 of October 19, 1987 (J Off République Française, October 20, 1987, pp. 12245-12248), and the recommendations from the Centre National de la Recherche Scientifique. Embryonic mouse SCs were obtained as previously described (Delpy et al., 2008). Briefly, pregnant mice were anesthetized by intramuscular injection of a mix of ketamine and xylazine and killed using a lethal dose of $\mathrm{CO}_{2}$. Embryos of either sex were removed, and the SC was isolated. Whole SCs were then maintained for $1 \mathrm{~h}$ in ACSF containing $114.5 \mathrm{~mm} \mathrm{NaCl}, 25 \mathrm{~mm} \mathrm{NaHCO}, 1 \mathrm{~mm}$ $\mathrm{NaH}_{2} \mathrm{PO}_{4}, 3 \mathrm{~mm} \mathrm{KCl}, 11 \mathrm{~mm}$ glucose, $2 \mathrm{~mm} \mathrm{CaCl}$, and $1 \mathrm{~mm} \mathrm{MgCl}_{2}$ (307 mosmol $/ \mathrm{kg} \mathrm{H}_{2} \mathrm{O}$ ), continuously bubbled with a $95 \% \mathrm{O}_{2}-5 \% \mathrm{CO}_{2}$ gas mixture. In some experiments in which the $[\mathrm{KCl}]_{\mathrm{o}}$ was increased, the following ACSF was used: $116 \mathrm{~mm} \mathrm{NaCl}, 25 \mathrm{~mm} \mathrm{NaHCO}, 1 \mathrm{~mm}$ $\mathrm{NaH}_{2} \mathrm{PO}_{4}, 7 \mathrm{~mm} \mathrm{KCl}, 11 \mathrm{~mm}$ glucose, $2 \mathrm{~mm} \mathrm{CaCl}_{2}$, and $1 \mathrm{~mm} \mathrm{MgCl}_{2}(322$ $\mathrm{mosmol} / \mathrm{kg} \mathrm{H}_{2} \mathrm{O}$ ).

Whole-cell recordings and analysis. The isolated SC was placed in a recording chamber and continuously perfused $(1.9 \mathrm{ml} / \mathrm{min})$ at room temperature $\left(20^{\circ} \mathrm{C}-24^{\circ} \mathrm{C}\right)$ with the oxygenated ACSF described above. Whole-cell voltage-clamp recordings of lumbar spinal MNs were performed under direct visualization using an infrared-sensitive CCD video camera. MNs were distinguishable by their size and location in the ventral area of the SC. To confirm MN identity, some recorded cells were filled with neurobiotin $(2-4 \mathrm{mg} / \mathrm{ml})$ and revealed in combination with Islet1/2 staining (Scain et al., 2010). Whole-cell patch-clamp electrodes were pulled from thick-wall borosilicate glass using a Brown-Flaming puller (Sutter Instrument). The tip of the electrode was fire-polished using a microforge (Narishige). Patch-clamp electrodes had resistances of $4-6 \mathrm{~m} \Omega$. For voltage-clamp experiments, the electrode was filled with a solution containing the following: $130 \mathrm{~mm} \mathrm{CsCl,} 4 \mathrm{~mm} \mathrm{MgCl}_{2}, 4 \mathrm{~mm}$ $\mathrm{Na}_{3} \mathrm{ATP}, 10 \mathrm{~mm}$ EGTA, and $10 \mathrm{~mm}$ HEPES, pH 7.2 (290 mosmol $/ \mathrm{kg}$ $\mathrm{H}_{2} \mathrm{O}$ ). In such conditions, the equilibrium potential for chloride ions $\left(\mathrm{E}_{\mathrm{Cl}}\right)$ was $\sim 3 \mathrm{mV}$. In some voltage-clamp experiments in which $\mathrm{ECl}$ was set at $\sim-60 \mathrm{mV}$, the electrode contained the following: $110 \mathrm{~mm} \mathrm{Cs}$ gluconate, $4 \mathrm{~mm} \mathrm{CsCl}, 4 \mathrm{~mm} \mathrm{MgCl}_{2}, 4 \mathrm{~mm} \mathrm{Na}_{3} \mathrm{ATP}, 10 \mathrm{~mm}$ EGTA, and 10 mM HEPES, pH $7.2\left(290 \mathrm{mosmol} / \mathrm{kg}-\mathrm{H}_{2} \mathrm{O}\right)$. The junction potential (12.6 $\mathrm{mV}$ ) was systematically corrected. For current-clamp recordings, the electrode contained the following: $105 \mathrm{~mm} \mathrm{~K}$-gluconate, $25 \mathrm{~mm} \mathrm{KCl}, 5$ mM NaCl, 10 mM HEPES, 2 mm MgATP, and 1 mm EGTA, pH 7.4 (285 mosmol/kg- $\left.\mathrm{H}_{2} \mathrm{O}\right)$. The junction potential $(12.1 \mathrm{mV})$ was systematically corrected. Using these gluconate solutions, $\mathrm{E}_{\mathrm{Cl}} \sim-35 \mathrm{mV}$ was close to the physiological values measured at E12.5 on spinal MNs (Delpy et al., 2008).

Signals were recorded using an Axopatch 200B or a Multiclamp 700B amplifier (Molecular Devices). Data were low-pass filtered $(2 \mathrm{kHz})$, digitized $(20 \mathrm{kHz})$ online using a Digidata $1322 \mathrm{~A}$ interface, and acquired using PClamp 9.2 software (Molecular Devices). Analyses were performed off-line using PClamp 9.2 software package and Axograph X.1.3.5 software (AxoGraph Scientific Software). In voltage-clamp experiments, spontaneous activity was recorded at a holding potential of $-60 \mathrm{mV}$, whereas in current-clamp experiments it was recorded at values closed to the measured resting membrane potential $\left(\mathrm{V}_{\mathrm{m}}=-60.8 \pm 1.32\right.$ $\mathrm{mV} ; N=5)$.

To estimate the theoretical membrane potential depolarization value at the peak of GDPs according to the maximum intensity of recorded spontaneous giant inward currents (GICs), in the absence or presence of different antagonists, we first calculated the chord conductance at the peak of GICs when the membrane potential was held at $\mathrm{V}_{\mathrm{h}}-60 \mathrm{mV}$. For this calculation, the intracellular solution was set to obtain an equilibrium potential for chloride close to $0 \mathrm{mV}$, which was then equal to the equilibrium potential for cationic ions. GABAergic, glycinergic, and glutamatergic components of GICs were estimated in the presence of specific antagonists of the corresponding receptors. The chord conductance $(g x)$ was calculated as follows:

$$
g x=\frac{\operatorname{Igic}}{([E-E x])}
$$

where $g x$ is the chord conductance for the ionic species $x$, Igic is the peak current, $E$ is the holding potential $(-60 \mathrm{mV})$, and $E x$ is the equilibrium potential for the ionic species $x(0 \mathrm{mV})$.

The expected depolarization evoked by the maximum change in conductance during GIC in response to $\mathrm{GABA}_{\mathrm{A}} \mathrm{R}$, glutamate, and/or glycine receptor activation was calculated using the following equation:

$$
\Delta V=\frac{g x([E-E x])+g y([E-E y])+g z([E-E z])}{\text { Ginput }+g x+g y+g z}
$$

where $\Delta V$ is the depolarization value from the resting membrane potential $(E), g x, g y$, and $g z$ are the chord conductances of the $x, y$, or $z$ GIC ionic components, and $E x, E y$, and $E z$ are the respective equilibrium potentials, and $\mathrm{G}_{\text {input }}$ is the input conductance of the cell at the $-60 \mathrm{mV}$ resting membrane potential (Ginput $\left.=\frac{1}{\text { Rinput }}\right)$.

In Equation 2, Ginput $+g x+g y+g z$ takes into account the shunting effect evoked by the decrease in input resistance $\left(R_{\text {input }}\right)$ during a GDP. When a specific conductance (GABAergic, glutamatergic, and/or glycinergic) was blocked, the corresponding $g$ value was set to 0 . According to the slow time course of GICs (see Results), the effect of the cell capacitance was neglected. $\Delta V$ in physiological conditions was calculated using a chloride equilibrium potential of $-35 \mathrm{mV}$ (Delpy et al., 2008).

Spontaneous synaptic events were detected using a Variable Amplitude Template method (AxoGraph Scientific Software). Postsynaptic 
Table 1. Primary antibodies ${ }^{a}$

\begin{tabular}{|c|c|c|c|c|}
\hline Primary antibody & Company & Reference & Host/isotype & $\overline{\text { Dilution }}$ \\
\hline Anti-VIAAT & Provided by B. Gasnier, Institut de Biologie physico-chimique, Paris & Dumoulin et al., 1999 & Rabbit polyclonal & $1: 1000$ \\
\hline Anti-VGlut2 & Provided by S. El Mestikawy, INSERM U 952, UPMC, Paris & Herzog et al., 2001; Borgius et al., 2010 & Rabbit polyclonal & $1: 5000$ \\
\hline Anti-VGlut1 & Provided by S. El Mestikawy, INSERM U 952, UPMC, Paris & Herzog et al., 2001; Borgius et al., 2010 & Rabbit polyclonal & $1: 1000$ \\
\hline Anti-GFP & Invitrogen & A10262 & Chicken polyclonal & $1: 1000$ \\
\hline Anti-synaptophysin & Sigma-Aldrich & SVP-38 & Mouse monoclonal & $1: 200$ \\
\hline
\end{tabular}

aINSERM, Institut National de la Santé et de la Recherche Médicale; UPMC, Université Pierre et Marie Curie.

currents were observed during evoked GICs (eGICs) or during the application of ACh in the absence or presence of TTX (miniature postsynaptic currents). We observed two classes of postsynaptic currents. One class had a short duration (half-amplitude duration $<3 \mathrm{~ms}$ ), and the other class had a duration $>10$ times longer (half-amplitude duration $>20$ $\mathrm{ms})$. Accordingly, different templates were defined to detect short or long synaptic events by selecting a representative event for each trace analyzed. An event was detected when the amplitude of the scaled template, divided by the mismatch between the template and the signal, exceeded a predefined level. Each event was accepted or rejected on the basis of their time courses. To analyze event duration, postsynaptic events were aligned at $10 \%$ amplitude of the ascending phase. Event width was measured at $50 \%$ of the peak amplitude.

Extracellular recordings. In the same experimental conditions as for whole-cell recordings, spontaneous activity was recorded extracellularly from E12.5 SCs using a glass electrode placed into the ventral cord and connected to a high-gain a.c. amplifier (ISO-DAM8A-4 Bio-amplifier System, World Precision Instruments). Filtered (filter cutoff frequency: $0.3-3 \mathrm{kHz}$ ) raw signals were integrated offline and analyzed using Spike2 software (Cambridge Electronic Design). Changes in burst area and burst duration were calculated from lumbar recordings.

Pharmacological agents. During patch-clamp recordings, all drugs were applied using $0.5-\mathrm{mm}$-diameter quartz tubing positioned $50 \mu \mathrm{m}$ away from the recording area under direct visual control. The quartz tubing was connected using a manifold to 6 solenoid valves linked with six reservoirs. Solutions were gravity-fed into the quartz tubing. Drug application was controlled using a VC-8 valve controller (Warner Instruments).

The following pharmacological agents were used: ACh $(100 \mu \mathrm{M}$, Sigma-Aldrich), TTX $(0.3-1 \mu \mathrm{M}$, Latoxan), gabazine (3 $\mu \mathrm{M}$, Tocris Bioscience), strychnine hemisulfate salt (0.5-3 $\mu \mathrm{M}$, Sigma-Aldrich) (+)D-tubocurarine chloride (10 $\mu \mathrm{M}$, Tocris Bioscience), mecamylamine (50-100 $\mu \mathrm{M}$, Tocris Bioscience), dihydro- $\beta$-erythroidine hydrobromide (DH $\beta$ E, $5 \mu \mathrm{M}$, Tocris Bioscience), QX314 (1 mM, Sigma-Aldrich), $20 \mu \mathrm{M}$ CNQX (Tocris Bioscience), and DL-2-amino-5-phosphonopentanoic acid (DL-APV, $200 \mu \mathrm{M}$, Tocris Bioscience). All these drugs, except QX314, were dissolved in the bath solution. QX314 was dissolved in the intracellular solution. It was used to block action potentials when GICs were evoked by the application of a high extracellular $\mathrm{K}^{+}$solution. We also used the proton pump inhibitor bafilomycin A1 $(4 \mu \mathrm{M}$, Tocris Bioscience), which was dissolved in DMSO as a stock solution (final proportion: $0.1 \%$ DMSO). SCs were incubated for $1 \mathrm{~h}$ in the presence of bafilomycin A1 before recordings. Bath solution containing 0.1\% DMSO did not affect $\mathrm{MN}$ activity (data not shown).

Meclofenamic acid (Sigma-Aldrich), 18 $\alpha$-glycyrrhetinic acid (SigmaAldrich), and $18 \beta$-glycyrrhetinic acid were used to block gap junctions (Guan et al., 2007; Giaume and Theis, 2010). 18 $\beta$-Glycyrrhetinic acid is more potent than $18 \alpha$-glycyrrhetinic acid in blocking gap junctions (Guan et al., 2007). However, these compounds have some side effects on voltage-gated channels: $18 \alpha$-glycyrrhetinic acid and $18 \beta$-glycyrrhetinic acid inhibit delayed rectifier $\mathrm{K}^{+}$channels (Guan et al., 2007) and may increase SC neuron excitability, whereas meclofenamic acid inhibits voltage-gated $\mathrm{K}^{+}$channels and alters GABA-activated currents (Juszczak and Swiergiel, 2009). Accordingly, to prove that gap junctions control embryonic SC activity, $18 \beta$-glycyrrhetinic acid and meclofenamic acid must at least have similar inhibitory effects on spontaneous embryonic SC electrical activity. We did not use carbenoxolone because it inhibits calcium channels (Giaume and Theis, 2010), increases the action potential threshold, and strongly decreases the firing rate of the neuronal net- work in the absence of gap junctions, at least in primary cultures of hippocampus (Giaume and Theis, 2010). 18 $\alpha$-Glycyrrhetinic acid and $18 \beta$-glycyrrhetinic acid were prepared in DMSO (final proportion: $0.1 \%$ DMSO), and meclofenamic acid was dissolved in the bath solution.

Immunohistochemistry. Hb9-eGFP transgenic mice in which an eGFP cDNA was expressed under the control of the mouse $H b 9$ promoter (Wichterle et al., 2002) were used to visualize spinal MNs. E12.5 embryos were collected from pregnant females. Once dissected out of their yolk sac, these embryos were immediately immersion-fixed in PBS with $2 \%$ PFA (freshly prepared in PBS, $\mathrm{pH} 7.4$ ) for $1 \mathrm{~h}$ at $4^{\circ} \mathrm{C}$. Embryos were then rinsed with PBS and cryoprotected in PBS $-20 \%$ sucrose at $4^{\circ} \mathrm{C}$. Tissues were embedded in OCT medium (VWR) and quickly frozen; $20-\mu \mathrm{m}-$ thick serial sections were collected onto slides using a cryostat. Immunostaining was processed on SC transverse sections. Sections were thawed at

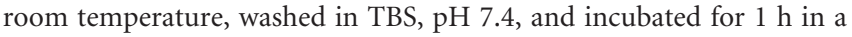
blocking solution ( $10 \%$ goat serum in TBS) with $0.4 \%$ Triton X-100 and then overnight at $4^{\circ} \mathrm{C}$ with the primary antibodies, which were diluted in the blocking solution containing $0.4 \%$ Triton $\mathrm{X}-100$. Sections were then washed in TBS and incubated for $2 \mathrm{~h}$ at room temperature in the secondary antibodies, diluted in $0.4 \%$ Triton X-100 blocking solution. After washing in TBS, slides were dried and mounted in Mowiol medium (Millipore).

All primary antibodies used and respective dilutions are listed in Table 1. To visualize the vesicular inhibitory amino acid transporter (VIAAT), we used a rabbit polyclonal anti-VIAAT antibody (kindly provided by B. Gasnier, Institut de Biologie physico-chimique, Paris), which recognizes the common presynaptic vesicular transporter of glycine and GABA (Dumoulin et al., 1999). To reveal the vesicular glutamate transporter VGluT2, expressed by glutamatergic INs in the SC and immature CNS, we used the rabbit polyclonal anti-VGluT2 antibody (Herzog et al., 2001; Borgius et al., 2010) (kindly provided by S. El Mestikawy, Institut National de la Santé et de la Recherche Médicale U 952, Université Pierre et Marie Curie, Paris). To stain the vesicular glutamate transporter VGluT1, we used a rabbit polyclonal anti-VGluT1 antibody (Herzog et al., 2001; Borgius et al., 2010) (kindly provided by S. El Mestikawy, Institut National de la Santé et de la Recherche Médicale U 952, Université Pierre et Marie Curie, Paris). We visualized synaptophysin using an antisynaptophysin monoclonal antibody (Sigma-Aldrich). To visualize MN fibers in HB9-eGFP mice, we used a chicken polyclonal anti-GFP antibody (Invitrogen). Staining was not observed in mice that do not express eGFP. Alexa Fluor 488- or 594-conjugated secondary antibodies (1/1000; Invitrogen) were used to detect mouse monoclonal, guinea pig, rabbit polyclonal, and chicken primary polyclonal antibodies.

Confocal microscopy. Preparations were analyzed using a Leica SP5 confocal microscope. VIAAT, VGluT1, and VGluT2 immunostaining was observed on embryo transverse sections using a $40 \times$ oil-immersion objective with a numerical aperture of 1.25 , as well as with a $63 \times$ oil-immersion objective with a numerical aperture of 1.32 and a $1.5 \times$ digital zoom magnification. Serial optical sections were obtained with a $Z$-step of $0.3 \mu \mathrm{m}(40 \times)$ and $0.21 \mu \mathrm{m}(63 \times)$. Images $(1024 \times 1024 ; 8$-bit grayscale) were stored using Leica software LAS-AF and analyzed using ImageJ 1.41 (National Institutes of Health; http://rsb.info.nih.gov/ij/) and Adobe Photoshop CS3 (Adobe software). Quantifications were performed on $20-\mu \mathrm{m}$-thick transverse sections using ImageJ software. Immunoreactive aggregates were selected by visually setting an intensity threshold, and images were adjusted in brightness and contrast. Confocal images were then transformed into binary images, and clusters were automatically detected with Image software. A cluster was defined as an object being 3 times larger than the XY confocal resolution $\left(0.05 \mu \mathrm{m}^{2}\right.$; red emission; $63 \times$ objective $)$ and having a 3 times 
higher intensity than the baseline noise. Density of VIAAT-, VGluT2-, and VGluT1immunoreactive aggregates was analyzed on a single confocal image every $5 \mu \mathrm{m}$ ( $Z$-stack) for each SC slice $(N=5$ slices per SC; $N=3-5$ SCs). A total of 5 images per stack were analyzed. The boundary between the ventral funiculus and the parenchyma was determined for each slice with respect to the DAPI staining, whereas the MN area was established by means of the eGFP staining. Synaptophysin-VIAAT, synaptophysin-VGluT2, and synaptophysinVGluT1 colocalizations were quantified using the JACoP plugin with the image processing package Fiji (distribution of ImageJ).

Statistics. All values are expressed as mean \pm SEM. Statistical significance was assessed by one-way ANOVA or by the nonparametric Kruskal-Wallis test with Dunn's post tests, Mann-Whitney test, or Wilcoxon matched pairs test (GraphPad Software).

\section{Results}

MN spontaneous electrical activity in mouse embryonic SCs at E12.5

Although a neuronal network model has been previously proposed to explain the early generation of spontaneous electrical activity in the mouse embryonic E12.5 SC (Hanson and Landmesser, 2003), the mechanisms triggering firing in $\mathrm{MNs}$ and their pattern of firing during spontaneous bursts of activity remain unknown. To address this issue, we used a combination of extracellular and whole-cell patch-clamp recordings to analyze the relationship between whole SC activity and single MN activity during spontaneous rhythmic activity at the E12.5 developmental stage. We first confirmed that $\mathrm{MN}$ ranged from 0.3 to $1 \mathrm{G} \Omega$, whereas their input capacitance was $>19 \mathrm{pF}$ as previously described (Delpy et al., 2008; Scain et al., 2010). During current-clamp recording $\left(\mathrm{V}_{\mathrm{m}}=-60 \mathrm{mV} ; \mathrm{ECl}=-35 \mathrm{mV}\right)$, spontaneous rhythmic MN activity was characterized by recurrent long-lasting GDPs occurring every $\sim 2-5$ min depending on the cell tested $(3.4 \pm 0.3 \mathrm{~min}$, $N=8$ ) (Fig. $1 A$ ). The interepisode interval was rather constant: $\mathrm{CV}$ (SD/mean; index of relative dispersion) of interepisode was $0.32 \pm 0.07(N=8)$. CV values were in the same range as those previously described for spontaneous activities recorded at E12.5 (Branchereau et al., 2002). Simultaneous extracellular recordings showed that these GDPs occurred at the same time as extracellular rhythmic bursts of activity, indicating that GDPs recorded on MNs were correlated with the spontaneous electrical activity of the embryonic SC (Fig. 1A). Measured at $50 \%$ of the peak amplitude, GDPs had a half-width of $1.04 \pm 0.09 \mathrm{~s}(N=10 \mathrm{MNs})$ and mean amplitude of $30.7 \pm 0.7 \mathrm{mV}$ from $\mathrm{V}_{\mathrm{m}}=-60 \mathrm{mV}(N=10)$. Despite the duration of the GDP and the value reached by the peak of depolarization $(\sim-30 \mathrm{mV})$ that was more depolarized than the action potential threshold value $(-40.7 \pm 1.1 \mathrm{mV}, \mathrm{N}=$ 5 ), we observed only 1-3 action potentials during the ascending and plateau phase of each GDP (Fig. $1 A$ ). This inability to repetitively spike during GDPs was probably the result of the intrinsic electrical properties of MNs at the early developmental stage (Gao and Ziskind-Conhaim, 1998) because MNs were unable to generate a burst of action potential when a suprathreshold depolarizing current step (250 ms duration) was applied ( $N=7$; data not shown).
To assess whether GDPs are the result of input currents driven by neurotransmitter release, we analyzed MN activity in the voltage-clamp mode. As for GDPs, we observed spontaneous GICs (sGICs) that were 1/1 correlated with SC rhythmic bursts of activity (Fig. $1 B$ ). sGICs had a mean amplitude of $478 \pm 56.5 \mathrm{pA}$ and were slow events, with a $20-80 \%$ rise time of $338 \pm 20 \mathrm{~ms}$ and a half-width of $0.68 \pm 0.05 \mathrm{~s}(N=42)$. sGICs were characterized by slow inward currents (Fig. $1 B$ ) on which fast currents of variable duration and amplitude could also be observed depending on the tested cells (Figs. $1 B$ and $2 A 2, B 2, D$; see Figs. $8 A 2, B 2$ and $9 A$ ). These fast currents displayed a typical time course of postsynaptic events (Fig. 2A2). Hyperpolarizing the cell did not prevent sGICs (data not shown), but their activity was fully suppressed in the presence of TTX $(1 \mu \mathrm{M})$ or in the absence of $\left[\mathrm{Ca}^{2+}\right]_{\text {out }}(N=5$; data not shown), indicating that occurrence of sGICs was dependent on action potential firing in the SC neuronal network.

sGICs are generated by recurrent release of GABA, glutamate, and glycine onto MNs

As GABAergic neurotransmission is supposed to be involved in spontaneous rhythmic SC activity (Branchereau et al., 2002; Hanson and Landmesser, 2003), we first tested the effect of the $\mathrm{GABA}_{\mathrm{A}} \mathrm{R}$ antagonist gabazine on sGIC activity $\left(\mathrm{V}_{\mathrm{h}}=-60 \mathrm{mV}\right)$ (Fig. 2A). To determine the relative conductance component for each neurotransmitter potentially involved in sGICs, we set intracellular chloride concentration to obtain an $\mathrm{ECl}$ value $(\sim 0$ $\mathrm{mV}$ ) close to the cationic equilibrium potential (Ecation $\sim 0$ $\mathrm{mV}$ ). The identical reversal potential for all neurotransmitter activated currents permitted direct calculation of the relative contribution to GICs of each neurotransmitter conductance. Application of $3 \mu \mathrm{M}$ gabazine significantly $(p<0.01)$ reduced the 

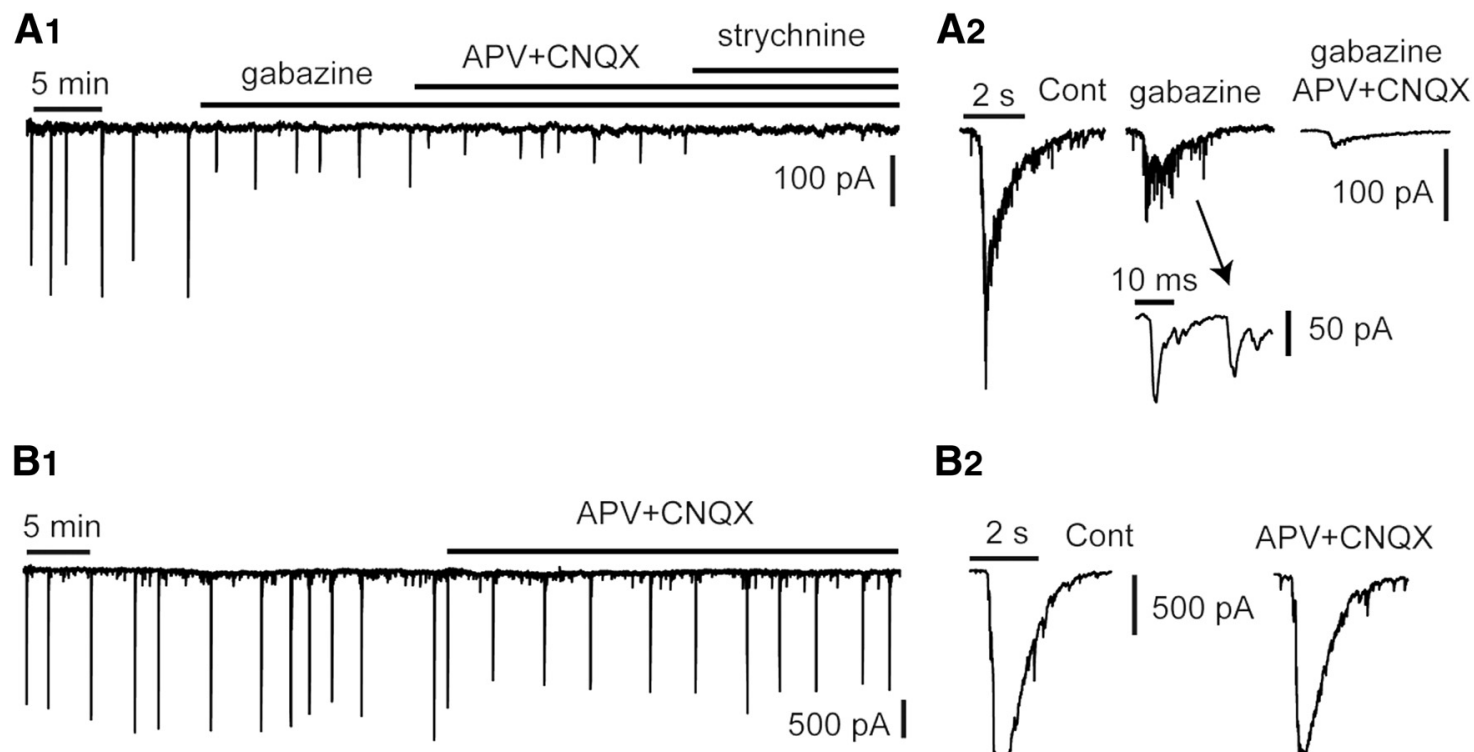

B2
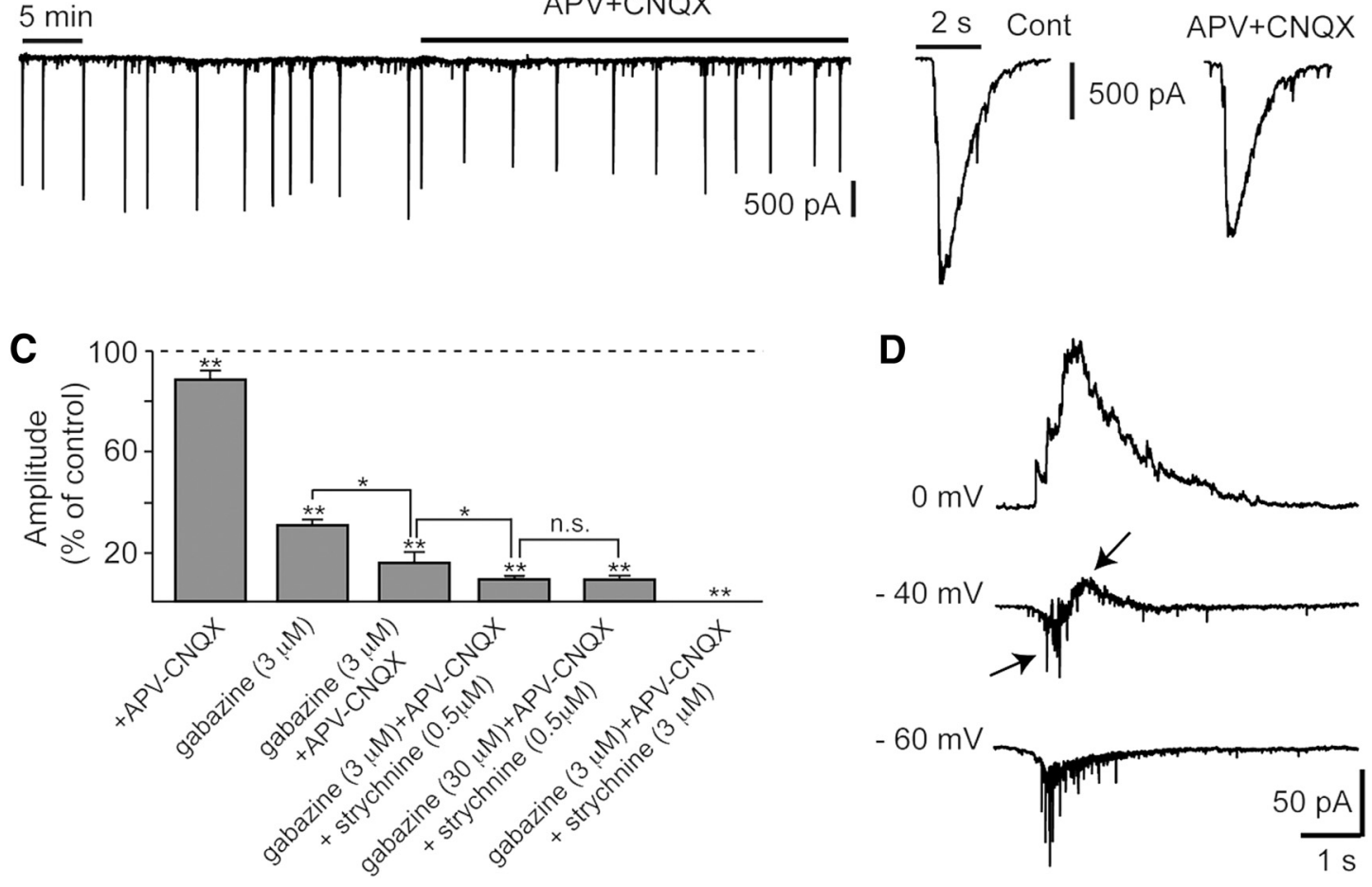

Figure 2. Simultaneous activation of $\mathrm{GABA}_{A}$, glutamate, and glycine receptors is involved in the generation of spontaneous $\mathrm{GICS}$. $A$, The application of the $\mathrm{GABA}_{A}$ receptor antagonist gabazine $(3 \mu \mathrm{M})$, the NMDA receptor antagonist DL-APV $(200 \mu \mathrm{M})$, plus the AMPA/kainate receptor antagonist CNQX (20 $\mu \mathrm{M})$ and the glycine receptor antagonist strychnine (3 $\mu \mathrm{m})$ fully blocks sGICs. There is a presence of fast synaptic currents in the presence of gabazine in $A 2 . V_{h}=-60 \mathrm{mV}$. B, Application of the glutamate receptor antagonists DL-APV (200 $\left.\mu \mathrm{M}\right)$ and CNQX (20 $\left.\mu \mathrm{M}\right)$ evoked a statistically significant reduction $\left(p<0.01\right.$ ) of $s \mathrm{GIC}$ amplitude as shown in C. C, Relative amplitude of s $\mathrm{GICs}$ (\% of control) in different pharmacological conditions (test vs control). Error bars indicate SEM. ${ }^{*} p<$ 0.05. ${ }^{* *} p<0.01$. n.s., Not significant. $\boldsymbol{D}$, Recording of $\mathrm{s} \mathrm{GICs}$ at different holding potentials with Echloride $=-60 \mathrm{mV}$ and Ecations $=0 \mathrm{mV}$. Setting $\mathrm{V}_{\mathrm{h}}=0 \mathrm{mV}$ reveals the chloride conductance component of $\mathrm{s} G \mathrm{ICS}$. Setting $\mathrm{V}_{\mathrm{h}}=-60 \mathrm{mV}$ reveals the cationic conductance component of $\mathrm{s} \mathrm{GICs}$. At $\mathrm{V}_{\mathrm{h}}=0 \mathrm{mV}, \mathrm{sGICs}$ were totally outward (top), whereas at $\mathrm{V}_{\mathrm{h}}=-60 \mathrm{mV}, \mathrm{sGICs}$ were totally inward (bottom). At $V_{h}=-40 \mathrm{mV}$, sGICs became biphasic and were composed of an early inward current followed by an outward current (middle).

sGIC amplitude by $70.6 \pm 3 \%$ corresponding to an average gabazine-sensitive conductance of $4.79 \pm 0.7 \mathrm{nS}(N=17)$ (Fig. $2 A 1, A 2)$ (control GIC conductance $=6.34 \pm 0.8 \mathrm{nS}, N=17$ ), without affecting sGIC half-width (97.8 $\pm 7.9 \%$ of control). In the presence of gabazine, the estimated remaining sGIC conductance ranged from 0.63 to $2.75 \mathrm{nS}$ (sGIC amplitude ranged from 38 to $165 \mathrm{pA}$; average amplitude: $100.8 \pm 8 \mathrm{pA} N=17$ ). The further addition of the NMDA receptor antagonist DL-APV (200 $\mu \mathrm{M})$ plus the AMPA/kainate receptor antagonist CNQX $(20 \mu \mathrm{M})$, significantly $(p<0.05)$ decreased the gabazine-insensitive sGIC amplitude by $55.2 \pm 4.6 \%(N=5)$ (Fig. $2 A, C)$. In the 5 cells tested, we estimated that this glutamatergic component of the sGIC (glutamatergic-dependent conductance: $1.09 \pm 0.2 \mathrm{nS}$, $N=5$; control GIC conductance: $5.44 \pm 0.9 \mathrm{nS}, N=5$ ) represented $21 \pm 4.7 \%$ of GIC conductance in these experimental conditions. When DL-APV and CNQX were applied alone, sGIC amplitude was significantly $(p<0.01)$ reduced by $11.3 \pm 1.6 \%$
$(N=8)$ (Fig. 2B, $C)$, being not significantly different $(p>0.05)$ from the percentage of the glutamatergic component estimated after gabazine application. In all recorded MNs, we also observed the persistence of gabazine-resistant fast events superimposed on sGICs (Fig. 2A2). These fast events had amplitudes ranging from 8 to $130 \mathrm{pA}(26 \pm 2.2 \mathrm{pA} ; N=10)$ with a half-width ranging from 1.26 to $2.26 \mathrm{~ms}(1.7 \pm 0.13 \mathrm{~ms} ; N=10)$. In the presence of CNQX and APV, these fast events were no longer observed $(N=12)$ (Fig. $2 A 2$ ), indicating that they may reflect the activation of glutamatergic receptors in response to a synaptic release of glutamate. CNQX application alone had no significant effect on GIC amplitude (data not shown).

sGICs were not completely suppressed in the presence of DLAPV, CNQX, and gabazine (Fig. $2 A$ ). This residual response corresponds to an estimated sGIC conductance of $0.82 \pm 0.08 \mathrm{nS}$ $(N=5)$ and could be the result of the spontaneous activation of postsynaptic glycinergic receptors (GlyRs) and/or postsynaptic 
nAChRs (Hanson and Landmesser, 2003). To address this issue, we assessed the effect of the GlyR antagonist strychnine on the residual spontaneous currents observed in the presence of gabazine (3 $\mu \mathrm{M})+$ DL-APV $(200 \mu \mathrm{M})$ and CNQX (20 $\mu \mathrm{M})$. We first tested the effect of the application of $0.5 \mu \mathrm{M}$ strychnine. It evoked a significant $(p<0.05) 43 \pm 8.6 \%$ decrease $(N=5)$ of gabazine, DL-APV-CNQXresistant sGICs (Fig. 2C). Interestingly, the time interval between GICs was significantly $(p<0.05)$ increased $(2.04 \pm 0.3$ times; $N=3$ ) in $0.5 \mu \mathrm{M}$ strychnine (data not shown), as previously shown in the presence of a higher strychnine concentration (Scain et al., 2010). Increasing the concentration of gabazine to $30 \mu \mathrm{M}$ did not affect $(p>0.1)$ the residual current observed in the presence of DL-APV, CNQX, and $0.5 \mu \mathrm{M}$ strychnine $(N=5)$ (Fig. 2C), suggesting that this current is not GABAergic. Gabazine, at this concentration, has little effect on embryonic glycine receptor (Li and Slaughter, 2007). However, increasing the strychnine concentration to $3 \mu \mathrm{M}$ fully blocked gabazine-, DL-APV-, and CNQX-resistant sGICs $(N=7)$ (Fig. $2 A 1, C)$. These findings cannot be the result of the inhibition of the SC neuronal network activity by strychnine because we have shown that SC activity is maintained in the presence of 3 $\mu \mathrm{M}$ strychnine alone (Scain et al., 2010). Accordingly, it is likely that the residual currents observed in the presence of gabazine, DL-APV, and CNQX indicate the occurrence of glycine release during sGIC activity.

Although these experiments indicate that GABA, glutamate, and glycine control sGDP activity, they cannot rule out indirect GABAergic, glycinergic, and glutamatergic transmissions on MNs. Indeed, the decrease in GIC amplitude observed in the presence of the different antagonists tested could also result from indirect effects due to block of GABAergic and/or glutamatergic postsynaptic inputs on other INs controlling MN activity. If sGICs resulted from direct activation of $\mathrm{GABA}_{\mathrm{A}}$, glycine, and glutamate receptors located on spinal MNs, sGICs must be a combination of GABA and glycine-dependent anionic currents and glutamate-dependent cationic currents. To address this issue, we analyzed sGICs when the equilibrium potential value for chloride $(\mathrm{ECl})$ and the equilibrium potential value for cations (Ecation) were set to -60 and $0 \mathrm{mV}$, respectively. GICs were then recorded at either $\mathrm{V}_{\mathrm{h}}=-60 \mathrm{mV}$ to reveal pure cationic currents, or at $\mathrm{V}_{\mathrm{h}}=0 \mathrm{mV}$ to reveal pure anionic currents, or at an intermediate $V_{h}$ value to determine the time course of appearance of cationic and anions currents during a GIC. As shown in Figure $2 D$, spontaneous giant currents were observed both at $V_{h}=0 \mathrm{mV}$ and $\mathrm{V}_{\mathrm{h}}=-60 \mathrm{mV}$, indicating that sGICs are a combination of cationic and anionic currents. Recorded at $\mathrm{V}_{\mathrm{h}}=0 \mathrm{mV}$, MNs generated giant outward currents with a mean amplitude of $171.1 \pm 37 \mathrm{pA}(N=7)$ and a half-width of $0.66 \pm 0.11 \mathrm{~s}(N=7)$, which were fully blocked by gabazine plus strychnine. Recorded
A2

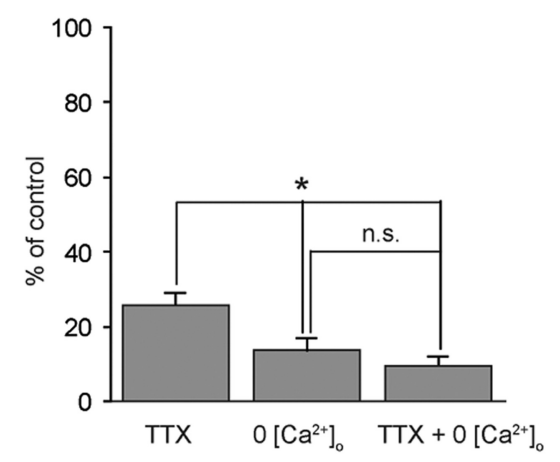

B2

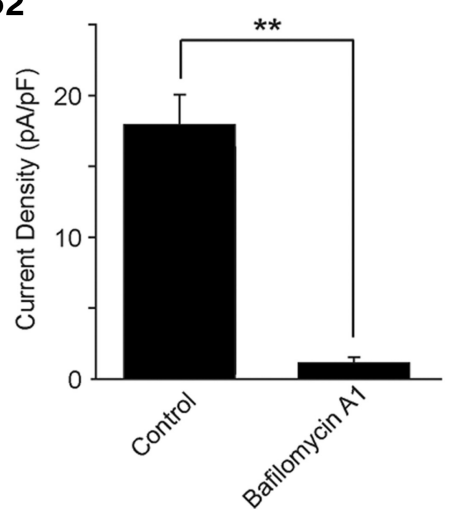

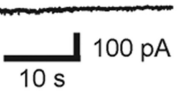

$30 \mathrm{mM} \mathrm{KCl}+\mathrm{TTX}$

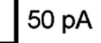

$5 \mathrm{~s}$
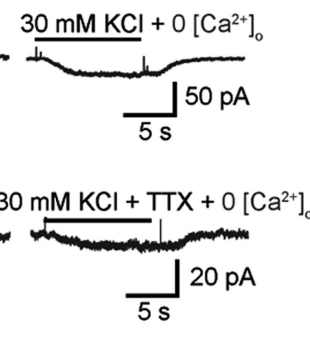

ontrol
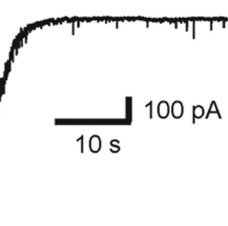

GICs evoked by neuronal network depolarization are dependent on vesicular release of neurotransmitters. $\boldsymbol{A 1}, \boldsymbol{B 2}$ ence of tetrodotoxin ( $0.3 \mu \mathrm{M}$ TTX) or in the absence of external calcium. Decreasing external calcium concentration ( $0 \mathrm{~mm}$ $\left.+4 \mathrm{~mm}\left[\mathrm{MgCl}_{2}\right]_{0}\right)$ is more efficient than TTX in affecting the amplitude of the evoked current. Adding TTX in the absence nt density (pA/pF) of eGICs in control and after $1 \mathrm{~h}$ of preincubation with bafilomycin $A 1 .{ }^{*} p<0.5{ }^{* *} p<0.01$. n.S., Not

at $\mathrm{V}_{\mathrm{h}}=-60 \mathrm{mV}, 6$ of $7 \mathrm{MNs}$ generated inward currents characterized by a slow component with a mean amplitude of $29.2 \pm 7.8$ pA and a half-width of $0.72 \pm 0.14 \mathrm{~s}(N=6)$ and fast synaptic-like currents with a mean amplitude at the peak of $61.5 \pm 11 \mathrm{pA}$ and a half-width of $2.4 \pm 0.26 \mathrm{~ms}(N=6)$. These inward currents were fully blocked by DL-APV plus CNQX. These results indicate that $\mathrm{sGIC}$ result from a direct activation of $\mathrm{GABA}_{\mathrm{A}}$, glycine, and glutamate receptors. When $\mathrm{V}_{\mathrm{h}}$ was set at an intermediate value between $\mathrm{ECl}$ and Ecations (from -20 to $-40 \mathrm{mV}$, depending on the cell tested), sGIC had a complex time course characterized by an early inward current followed by an outward current (Fig. 2D). According to ECl and Ecation values, inward currents were mainly carried by cation influx whereas outward currents were mainly carried by anion efflux. In addition, recordings performed at $\mathrm{V}_{\mathrm{h}}=0 \mathrm{mV}$ and $-60 \mathrm{mV}$ confirm that, during an sGIC, the glutamatergic cationic component occurred first and then superimposed on the GABA/glycine anionic GIC component (Fig. 2D).

These results demonstrate that sGICs are complex spontaneous currents resulting from sequential events involving first the activation of glutamate receptors followed by the activation of GABA and glycine receptors on MNs. They also indicate that embryonic E12.5 MN activity is driven by both direct glutamatergic and GABAergic/glycinergic inputs. Moreover, these data 
A1

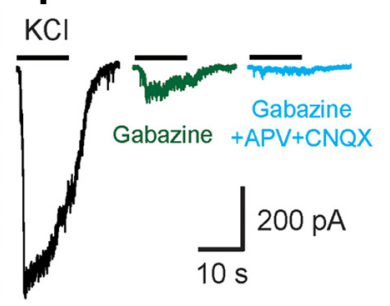

A2

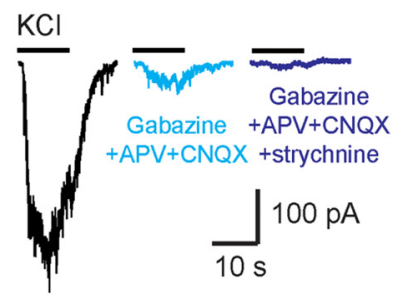

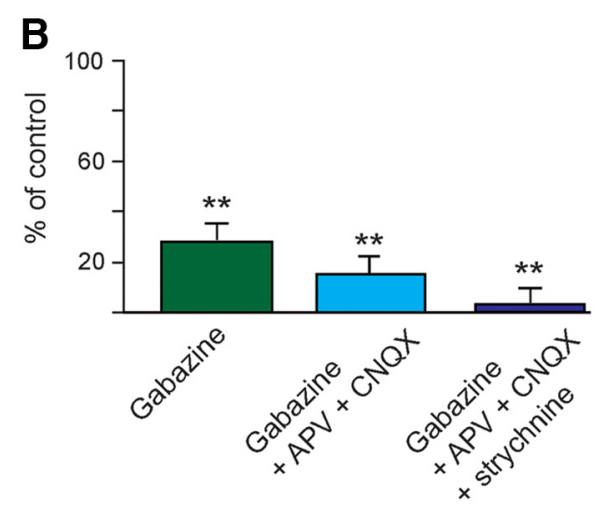

Figure 4. Evoked GICs reflect simultaneous release of GABA, glutamate, and glycine. A1, Example of inward currents evoked by the application of high $\mathrm{K}^{+}$solutions $(30 \mathrm{~mm})$ in control conditions (black), in the presence of the $G A B A_{A}$ Rantagonist gabazine $(3 \mu \mathrm{M})$ (green) and in the presence of gabazine + glutamate receptor antagonists DL-APV (200 $\mu \mathrm{M})$ and CNQX $(20 \mu \mathrm{M})$ (light blue). $V_{h}=-60 \mathrm{mV}$. A2, Example of inward currents evoked by the application of high $\mathrm{K}^{+}$solutions $(30 \mathrm{~mm})$ in control conditions (black), in the presence of gabazine $(3 \mu \mathrm{m})+$ glutamate receptor antagonists (200 $\mu \mathrm{m}$ APV and $20 \mu \mathrm{M}$ CNQX) (light blue) and in the presence of gabazine, APV + CNQX, and the glycine receptor antagonist strychnine ( $3 \mu \mathrm{m}$ ) (dark blue). $V_{h}=-60 \mathrm{mV} . B$, eGICs are almost abolished by the addition of strychnine to the solution containing both gabazine and the glutamate receptor antagonists DL-APV and CNQX. ${ }^{* *} p<$ 0.01 .

may also suggest the absence of functional cholinergic inputs on MNs at this developmental stage.

\section{Evoked global SC network depolarization induces GICs on MNs}

To better characterize the nature and the mechanisms of neurotransmitter release that regulates $\mathrm{MN}$ activity in the early embryonic SC, we analyzed MN inward currents after application of high $\mathrm{K}^{+}$solution (30 mM) (Fig. 3). Indeed, high potassium solution is expected to depolarize all neurons, resulting in their artificial synchronization, which enables determination of which neurotransmitters are released on MNs upon global depolarization of the SC network.

Applications of high $\mathrm{K}^{+}$solution evoked GICs with an amplitude ranging from 103 to $1655 \mathrm{pA}$ depending on the recorded MNs (421.1 $\pm 31.1 \mathrm{pA} ; N=99)$. Evoked GICs (eGICs) were strongly dependent on action potential- and calcium-dependent synaptic releases of neurotransmitters. As expected, they were significantly decreased by $71.1 \pm 3.9 \%(p<0.01 ; N=5)$ in the presence of TTX and by $96.1 \pm 2.8 \%(p<0.01 ; N=5)$ in the absence of $\left[\mathrm{Ca}^{2+}\right]_{\text {out }}$ (Fig. $\left.3 A 1, A 2\right)$. Adding TTX in $0\left[\mathrm{Ca}^{2+}\right]_{\text {out }}$ evoked a $90.1 \pm 1.6 \%$ decrease of eGIC amplitude $(N=9)$, which is not significantly different from that observed in the absence of $\left[\mathrm{Ca}^{2+}\right]_{\text {out }}$ alone $(p>0.1)$ (Fig. 3A1,A2). The sensitivity of eGICs to TTX and to $\left[\mathrm{Ca}^{2+}\right]_{\text {out }}$ suggests that they mainly reflect activitydependent vesicular release of neurotransmitters. We thus examined the contribution of the vesicular release by preincubating the SC $\left(1 \mathrm{~h}\right.$ at $\left.35^{\circ} \mathrm{C}\right)$ with $4 \mu \mathrm{M}$ bafilomycin $\mathrm{A} 1$, an inhibitor of $\mathrm{V}$
(vacuolar)-ATPase, which prevents the entrance of neurotransmitters into synaptic vesicles and thereby impairs vesicular release (Cousin and Nicholls, 1997). Neurotransmitter release was analyzed on eGICs during whole-cell recording of MNs from SC treated with bafilomycin A1. The effect of bafilomycin A1 treatment was assessed by comparing eGIC current density $(\mathrm{pA} / \mathrm{pF})$ in the absence of bafilomycin with eGIC current density in the presence of bafilomycin. We previously showed that preincubation of SCs with bafilomycin A1 was able to completely abolish spontaneous or evoked synaptic activity recorded on embryonic MNs (Scain et al., 2010). Under these conditions, eGICs were strongly reduced (Fig. 3B1). eGIC current density was reduced by $94 \pm$ $2 \%(N=5)$ on MNs at E12.5 (Fig. 3B2), which confirmed that GICs result mainly from neurotransmitter vesicular release.

To determine the pharmacological profile of the $\mathrm{KCl}$-evoked current on recorded MNs, we first tested the effects of the $G_{A B A} R$ antagonist gabazine on eGICs and showed that eGIC amplitude was significantly decreased by $70.7 \pm 1.6 \%$ in the presence of gabazine ( 3 $\mu \mathrm{M})(p<0.01 ; N=83)$ (Fig. $4 A 1, B)$. Furthermore, eGICs were also dependent on glutamate receptor activation. Addition of DL-APV $(200 \mu \mathrm{M})$ and CNQX $(20 \mu \mathrm{M})$ to the gabazine solution resulted in an additional decrease of $16.4 \pm 2.9 \%$ of the eGIC amplitude $(p<0.05$; $N=5)$ (Fig. $4 A 1, B)$. When applied alone, DL-APV $(200 \mu \mathrm{M})$ and CNQX $(20 \mu \mathrm{M})$ significantly reduced by $20.7 \pm 2.8 \%(p<0.05 ; N=$ 8) eGIC amplitude. As shown in Figure $4 A 1, A 2$, a residual current representing $12.8 \%$ of the control response persisted in the presence of gabazine, APV, and CNQX. The addition of $3 \mu \mathrm{M}$ strychnine to the antagonist solution evoked a further significant decrease in eGIC amplitude $(p<0.01)$. eGIC amplitude was decreased by $95.8 \pm$ $0.5 \%(N=5)$ (Fig. $4 A 2, B)$ in the presence of gabazine, APV, CNQX, and strychnine and was therefore almost abolished. This indicates that the $\mathrm{KCl}$-evoked current, like spontaneous GICs on MNs, was likely the result of the release of GABA, glutamate, and glycine from presynaptic terminals targeting spinal MNs.

\section{Staining of the GABA vesicular transporter VIAAT and of glutamate vesicular transporters VGluT1 and VGluT2 in the ventral SC at E12.5}

According to our results obtained using bafilomycin A1 and high external $\mathrm{K}^{+}$solution, the vesicular transporter for GABA/glycine and glutamate should be expressed in E12.5 mouse SCs in the vicinity of MNs. To assess the relevance of this hypothesis, we performed immunostaining on SCs from E12.5 HB9-eGFP mouse embryo (Wichterle et al., 2002) with antibodies directed against the GABA/glycine vesicular transporter VIAAT (Sagné et al., 1997; Chaudhry et al., 1998) and the glutamate vesicular transporters VGluT1 (Takamori et al., 2000) and VGluT2 (Kaneko and Fujiyama, 2002).

At E12.5, VIAAT immunostaining was mainly localized within the ventral funiculus (Fig. 5A1,A2), as previously mentioned (Scain et al., 2010). VIAAT immunostaining was punctiform as expected for vesicular staining (Fig. 5A3,A4). VIAAT-immunoreactive aggregate density in the funiculus $\left(0.053 \pm 0.002\right.$ aggregates $\left./ \mu \mathrm{m}^{2} ; N=5 \mathrm{SC}\right)$ was significantly different $(p<0.01)$ from that in the motor column $\left(0.011 \pm 0.002\right.$ aggregates $\left./ \mu \mathrm{m}^{2} ; N=5 \mathrm{SC}\right)$. Some VIAAT clusters were apposed to $\mathrm{GFP}^{+}$profiles localized within the funiculus and within the motor columns (Fig. 5A3,A4, arrows). As observed for VIAAT immunostaining, VGluT2 (Fig. 5B) and VGluT1 (Fig. 5C) were mainly localized within the ventral funiculus (Fig. $5 B 1, B 2, C 1, C 2)$ and were punctiform (Fig. 5B3,B4,C3,C4, respectively). VGluT2immunoreactive aggregate density was $0.0497 \pm 0.0042$ aggregates/ $\mu \mathrm{m}^{2}(N=5 \mathrm{SC})$ in the ventral funiculus, a significantly higher value $(p<0.01)$ than the one detected in the MN area $(0.0127 \pm 0.0022$ 


\section{DAPI GFP VIAAT}

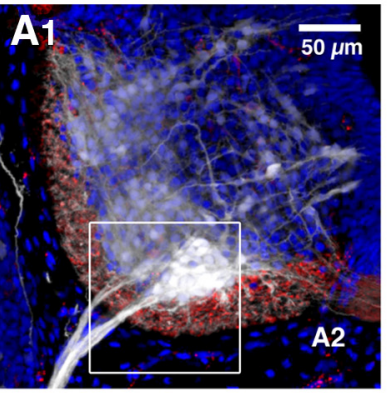

DAPI GFP VGLUT2

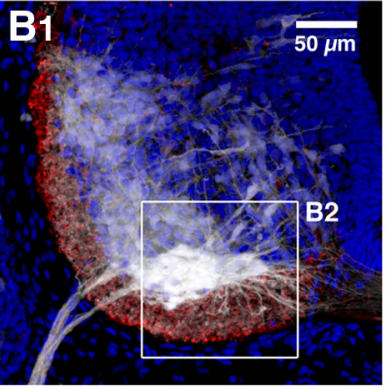

DAPI GFP VGLUT1

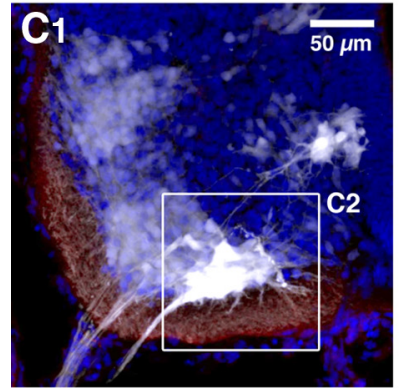

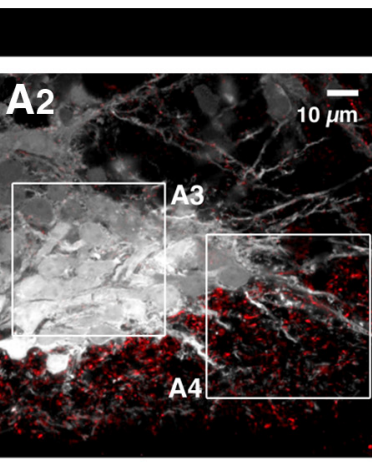

\section{GFP VIAAT}
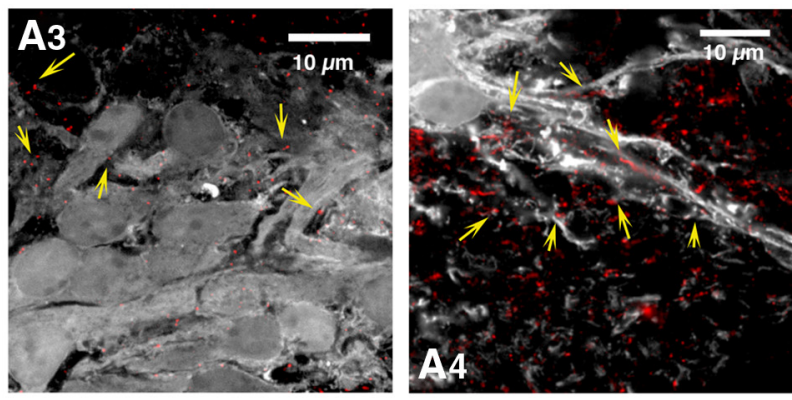

GFP VGLUT2
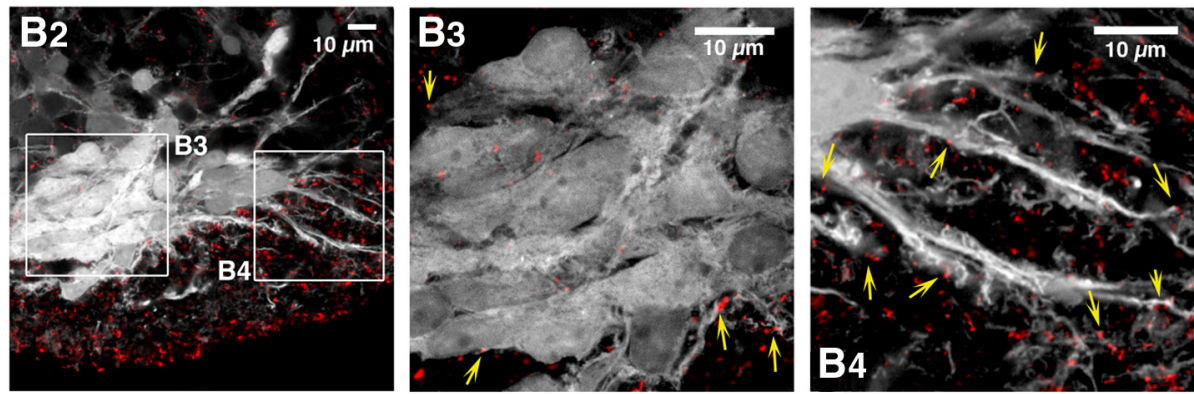

GFP VGLUT1
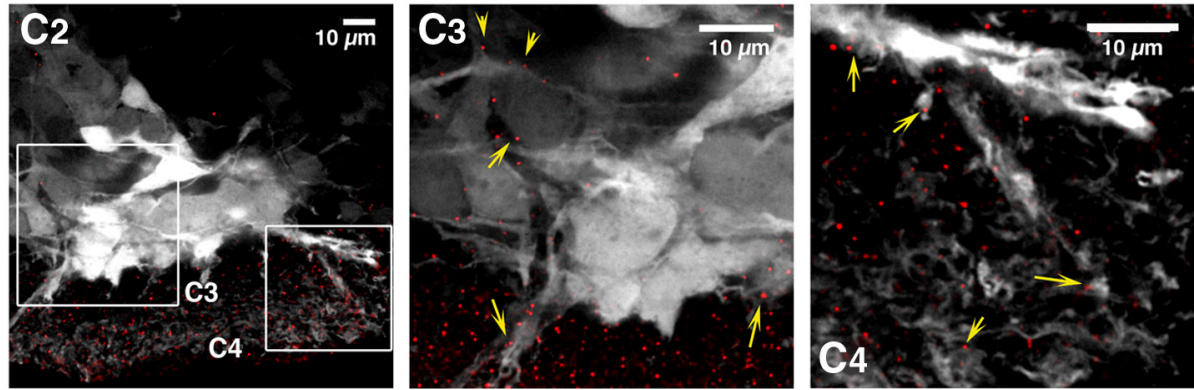

Figure 5. Expression of the vesicular transporters VIAAT for GABA and glycine and VGluT2 and VGluT1 for glutamate in the ventral horn of E12.5 HB9eGFP SCS. A1, B1, $\mathbf{2}$, MNs were visualized using GFP staining (white) and cell nuclei by DAPI staining (blue). A1, Vesicular transporter for GABA and glycine (VIAAT) immunostaining (red) in the SC of E12.5 HB9eGFP mouse embry0s. A2, VIAAT and GFP coimmunostaining in the area of the median motor column. A2, An enlargement of the boxed area shown in A1. A3, Single confocal section showing VIAAT immunostaining (red) within the MN pools (box A3 in A2). VIAAT staining is punctiform and surrounds MN cell bodies (arrows). A4, Single confocal section showing VIAAT immunostaining (red) within the ventral funiculus (box A4 in A2). There is a presence of MN dendritic-like profiles (eGFP staining, white) within the ventral funiculus. VIAAT immunostaining (red) is also punctiform in this area. VIAAT-immunoreactive aggregates can be apposed to MN dendritic-like extensions (arrows). B1, Immunostaining of the glutamate vesicular transporter VGluT2 (red) in the ventral SC area of E12.5 HB9eGFP mouse embryos. B2, Confocal image showing VGluT2 immunostaining in the area of the median motor column. $\boldsymbol{B} 2$, An enlargement of the boxed area shown in $\boldsymbol{B}$. $\mathbf{B}$, Single confocal section showing VGluT2 immunostaining (red) within the MN pools (box B3 in B2). As observed for VIAAT immunostaining, VGluT2 staining is punctiform. There is a presence of VGluT2-immunoreactive aggregates within the MN area (arrows). B4, Single confocal section showing VGluT2 immunostaining (red) within the ventral funiculus (box B4 in B2). The VGluT2-immunoreactive aggregates are equally apposed to MN GFP ${ }^{+}$extensions (arrows). C1, Immunostaining of the glutamate vesicular transporter VGluT1 (red) in the ventral SC area of E12.5 HB9eGFP mouse embryos. C2, Confocal image showing VGluT1 immunostaining in the area of the median motor column. An enlargement of the boxed area shown in C1. C3, Single confocal section showing VGluT1 immunostaining (red) within the MN pools (box C3 in C2). As observed for VGluT2 and VIAAT immunostaining, VGluT1 staining is punctiform. There is a presence of VGluT1-immunoreactive aggregates within the MN area (arrows). C4, Single confocal section showing VGluT1 immunostaining (red) within the ventral funiculus (box C4 in C2). The VGluT1-immunoreactive aggregates may be apposed to MN GFP ${ }^{+}$ extensions (arrows). A3, A4, B3, B4, C3, C4, Single confocal slices.

aggregates $\left./ \mu \mathrm{m}^{2}, N=5 \mathrm{SC}\right)$. VGluT1-immunoreactive aggregate density $\left(0.0329 \pm 0.0012\right.$ aggregates $\left./ \mu \mathrm{m}^{2} ; N=5 \mathrm{SC}\right)$ in the ventral funiculus was also significantly different $(p<0.01)$ from that in the $\mathrm{MN}$ area $\left(0.0042 \pm 0.0001\right.$ aggregates $\left./ \mu \mathrm{m}^{2} ; N=5 \mathrm{SC}\right)$. As observed for VIAAT staining, some VGluT2 and VGluT1 clusters were apposed to some $\mathrm{GFP}^{+}$elements localized within the funiculus and the motor columns (Fig. 5B3,B4,C3,C4, arrows). Most of the vesicular transporter staining in the funiculus is likely to reflect trafficking of vesicular proteins along the axon of newborn INs (Bury and Sabo, 2011). We performed double staining with antibodies directed against synaptophysin and VIAAT or VGluTs to determine the den- sity of putative functional release sites. Double staining with antibodies directed against synaptophysin and VIAAT or VGluTs (putative release site) showed that $11.8 \pm 0.5 \%(N=9)$ of VIAATimmunoreactive aggregates within the funiculus colocalized with synaptophysin-immunoreactive aggregates and $10.7 \pm 1 \%(N=9)$ of VGluT2-immunoreactive aggregates in the funiculus colocalize with synaptophysin-immunoreactive aggregates, as expected at this developmental stage (Fig. $6 A, B$ ). A total of $<5 \%$ of VGluT1immunoreactive aggregates $(4.3 \pm 0.7 \% ; N=8)$ colocalized with synaptophysin-immunoreactive aggregates at this age (Fig. 6C). These data are consistent with previous electron microscopy studies 


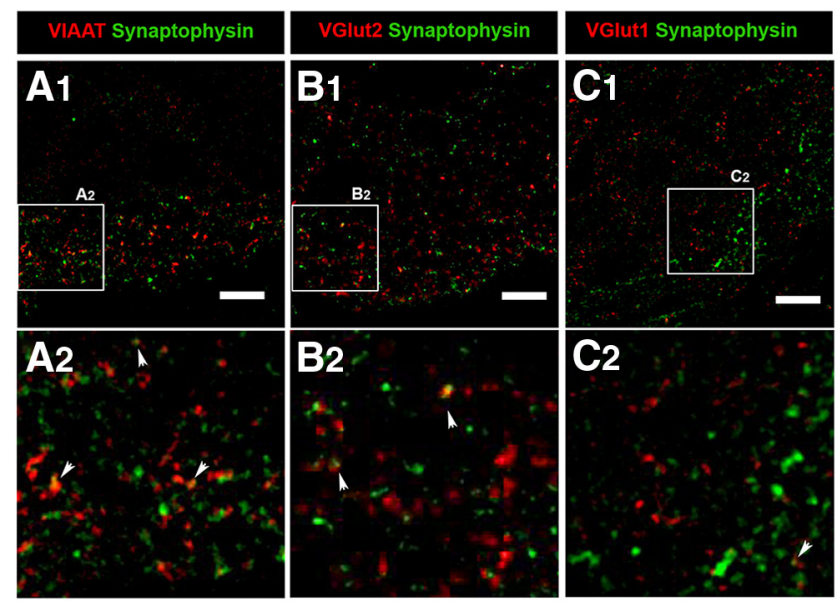

Figure 6. Double immunostaining using VIAAT, VGluT2, VGluT1, and synaptophysin in the ventral horn of E12.5 SCS. $\boldsymbol{A}$, VIAAT (red) and synaptophysin (green) immunostaining. $\boldsymbol{B}$, VGluT2 (red) and synaptophysin (green) immunostaining. C, VGluT1 (red) and synaptophysin (green) immunostaining. Scale bar, $10 \mu \mathrm{m}$. A2, An enlargement of the boxed area shown in $\mathbf{A 1}$. B2, An enlargement of the boxed area shown in B1. C2, An enlargement of the boxed area shown in C1 (colocalized stainings: arrows). A-C, Single confocal slices.

showing few synaptic contacts at E12.5 (Vaughn et al., 1977). These initial synaptic contacts on developing MNs at E12.5 were mainly localized on dendrite-like processes projecting within the ventral funiculus (Vaughn et al., 1977).

The presence of VGluT1 at this age is surprising because (1) it was supposed to be mainly expressed by proprioceptive afferent projection in the adult (Alvarez et al., 2004) and (2) DRG sensory projections do not yet invade the SC parenchyma of mouse embryo at E12.5 (Rigato et al., 2011). The observed VGluT1 staining is likely to be specific because VGlut1 staining was abolished in VGluT1 KO mice, suggesting that this antibody effectively recognizes VGluT1 (Siksou et al., 2013). It should be noted that VGluT1 staining in the adult was decreased by $50 \%$ only in SC lamina IX after local dorsal rhizotomy (Alvarez et al., 2004). Although the residual VGluT1 staining after dorsal rhizotomy could originate from long-range primary afferents projecting through several segments and thus spared by the rhizotomy procedure in the adult (Alvarez et al., 2004), it could also indicate that a subpopulation of SC INs can express VGluT1 in the SC. This could be the case in the embryonic SC.

\section{Relative involvement of GABA, glutamate, and glycine} components of sGIC in the control of sGDP amplitude Because of the high $\mathrm{R}_{\text {input }}$ of MNs (0.3-1 G $\Omega$ ), small-amplitude sGICs may be sufficient to evoke large sGDPs that depolarize the MN membrane potential to the action potential threshold $(\sim-40 \mathrm{mV})$. This point raises the question of the functional significance of the large amplitude of sGICs observed and of the relative role of the GABA, glycine, and glutamate GIC components, according to the evoked conductance changes with respect to the high $\mathrm{R}_{\text {input }}$ of MNs.

To address this issue, we first calculated the predicted membrane potential depolarization evoked by sGICs in control conditions and then after blocking $\mathrm{GABA}_{\mathrm{A}} \mathrm{Rs}$, as well as after blocking both $\mathrm{GABA}_{\mathrm{A}} \mathrm{Rs}$ and glutamate receptors to reveal the role of the different components of sGICs during sGDPs. We used the experimental conductance values for each sGIC component obtained in the five different MNs previously analyzed (see above: conductance of the GABA sGIC component $\sim 4.8 \mathrm{nS}$, con- ductance of the glutamate sGIC component $\sim 1.1 \mathrm{nS}$, and conductance of the glycine sGIC component $\sim 0.8 \mathrm{nS}$ ). To perform this calculation, we took into account the physiological $\mathrm{ECl}^{-}$ value $(-35 \mathrm{mV})$ (Delpy et al., 2008) and the shunting effect of the large conductance changes during GDPs with respect to the $\mathrm{R}_{\text {input }}$ of recorded MNs (see Materials and Methods). Depending on the cell considered, changes in conductance during sGICs are expected to depolarize the $\mathrm{MN}$ membrane potential to a value ranging from $-40 \mathrm{mV}$ to $-33.7 \mathrm{mV}$. This limited effect on $\mathrm{MN}$ membrane potential results from the shunting effect of the large conductance changes underlying sGICs with respect to the $\mathrm{R}_{\text {input }}$ of $\mathrm{MN}$ (see Eq. 2). Accordingly, the large increase in the input conductance evoked during a GIC could be a regulatory mechanism limiting the amplitude of GDPs.

The calculations predicted that blocking the GABA component of GICs has a limited effect on sGDP amplitude and varies from cell to cell (from a $5.7 \%$ to a $13.1 \%$ decrease). In the five cells analyzed, the $\mathrm{V}_{\mathrm{m}}$ value estimated at the peak of GDP ranged from $-42.8 \mathrm{mV}$ to $-32.2 \mathrm{mV}$, which predicted that the ability of MNs to fire action potential (AP) during GDP should not be strongly affected after losing its main GABAergic drive. Our calculations also predict that the glycine component of GICs (after blocking the GABA and the glutamate GIC component), although minor, is still able to evoke sGDPs with an amplitude ranging from 8.2 $\mathrm{mV}$ to $15.7 \mathrm{mV}$ from $\mathrm{V}_{\mathrm{m}}=-60 \mathrm{mV}$, which in turn depolarizes the $\mathrm{MN}$ membrane potential to a value between $-51.8 \mathrm{mV}$ and $-44.3 \mathrm{mV}$. However, in this case, GDPs evoked by glycine release only are predicted to be unable to trigger AP firing in MNs. Finally, our calculations predicted that the percentage decrease in GDP amplitude ranged from $6.7 \%$ to $25.3 \%$ when the glutamate component of GDPs was blocked. In this case, the $\mathrm{V}_{\mathrm{m}}$ value estimated at the peak of GDP ranged from $-45.1 \mathrm{mV}$ to $-37.4 \mathrm{mV}$, which predicted that the ability of an MN to fire AP during GDP should be affected in the same manner after losing its glutamatergic drive as after losing its main GABAergic drive. This may be surprising according to the relatively low proportion of the glutamatergic component compared with the GABAergic component, but this can be explained by the highly depolarized Ecation value $(0 \mathrm{mV})$ compared with $\mathrm{ECl}(-35 \mathrm{mV})$ and by the shunting effect of the large conductance change underlying the GABA component that reduced the amplitude of the evoked depolarization.

To determine whether these theoretical calculations are confirmed by physiological data, we compared our theoretical values with sGDPs recorded from spinal MNs of the various antagonists used to block sGICs (Fig. 6). In control conditions, sGDPs depolarized the $\mathrm{MN}$ membrane potential to a value ranging from -36 $\mathrm{mV}$ to $-21 \mathrm{mV}$ (mean $=-28.3 \pm 1.1 \mathrm{mV} ; 18 \mathrm{GDPs}, N=5)$ (Fig. $6 A, B)$. In the presence of gabazine $(3 \mu \mathrm{M})$, GDPs depolarized the $\mathrm{MN}$ membrane potential to a value between $-55 \mathrm{mV}$ and -26 $\mathrm{mV}$ (mean $=-37.1 \pm 1.6 \mathrm{mV} ; 25 \mathrm{sGDPs} ;=5$ ) that was significantly $(p<0.01)$ different from control values (Fig. $7 A 1, A 3)$. These data are consistent with predicted values, although the predicted sGDP amplitude in control conditions was slightly underestimated compared with experimental measurement. In control conditions, $84.67 \pm 11.62 \%$ of sGDPs evoked action potentials $(33 \%-100 \%$ of sGDPs, depending on the cell tested). In the presence of gabazine, $50.17 \pm 17.80 \%$ of sGDPs evoked action potentials and their efficacy in evoking action potentials was more variable ( $0 \%-100 \%$ of sGDPs depending on the tested cell), although the average percentage of sGDPs evoking action potentials was not significantly different from the control $(p>0.05)$ (Fig. 7A4). Finally, the depolarizing area of the sGDP 


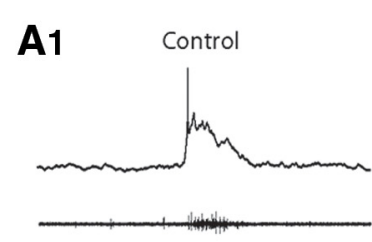

A2

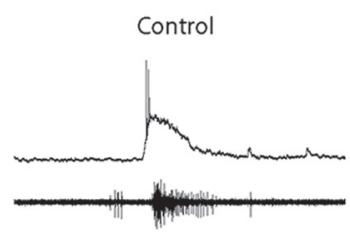

A3

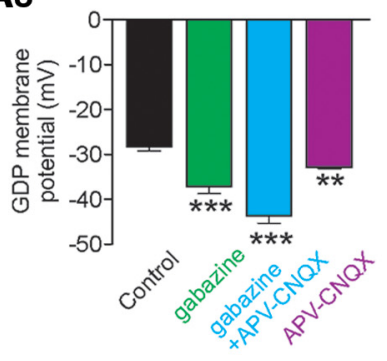

B

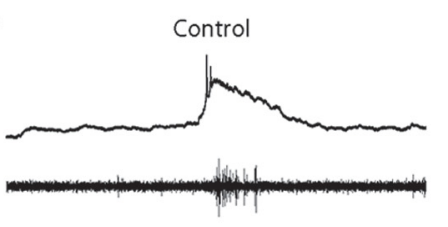

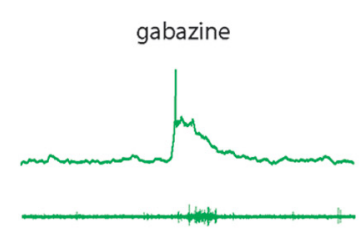
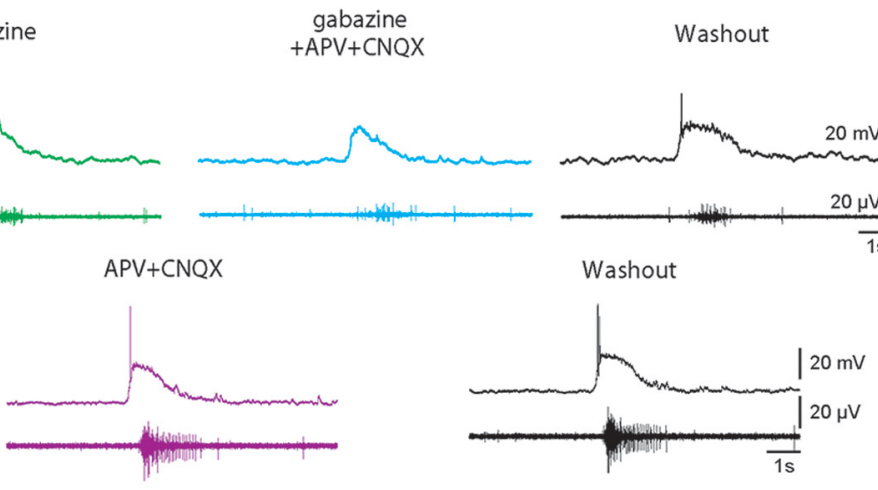

A4

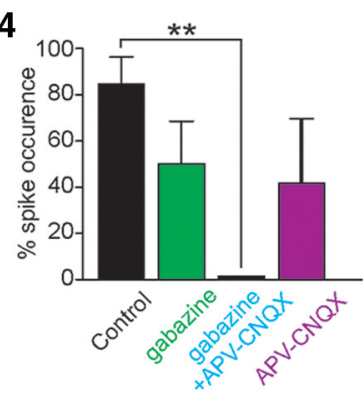

A5

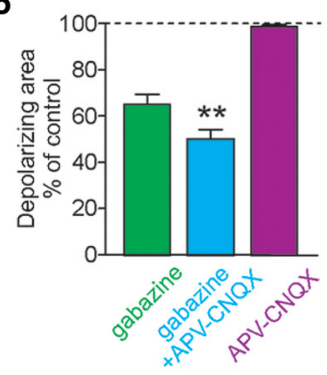

gabazine+APV+CNQX

+ Strychnine

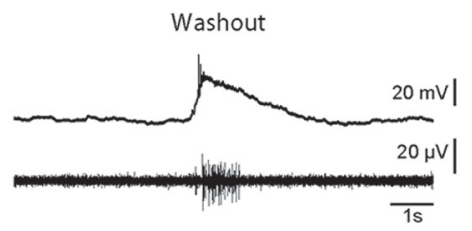

Figure 7. A simultaneous block of $\mathrm{GABA}_{\mathrm{A}}$ glutamate, and glycine receptors is required to fully inhibit both the SC local network activity and GDPs on MNs. A1, $\mathbf{A 2}$, Simultaneous extracellular recording of the SC spontaneous activity from lumbar motor networks and patch-clamp current-clamp recording of $s G D P s$ on lumbar MNs $\left(V_{m}=-60 \mathrm{mV}\right)$. SC spontaneous activity and the occurrence of sGDPs are mildly affected in the presence of gabazine ( $3 \mu \mathrm{m})$. Adding the glutamate receptor antagonists DL-APV (200 $\mu \mathrm{M})$ and CNQX (20 $\mu \mathrm{m})$ evokes a decrease of sGDP amplitude. Adding APV (200 $\mu \mathrm{M})$ and CNQX (20 $\mu \mathrm{M})$ alone slightly reduces MN excitability. Right traces, Recovery of the SC and MN activities after antagonist washout. A3, Quantitative analysis of changes in membrane potential at the peak of SGDPs in the absence or presence of the antagonists $\left(V_{m}=-60 \mathrm{mV}\right)$ (test vs control). A4, Quantitative analysis of MN firing propensity, expressed as a percentage of spike occurrence on sGDPs (test vs control). $\mathbf{A 5}$, Depolarizing area of GDPs in the absence or presence of the antagonists (test vs control). $\boldsymbol{B}$, Simultaneous extracellular recording of the SC spontaneous activity from lumbar motor networks and patch-clamp current-clamp recording of sGDPs on lumbar MNs $\left(\mathrm{V}_{\mathrm{m}}=-60 \mathrm{mV}\right)$ in the absence or presence of gabazine $+\mathrm{DL}-\mathrm{APV}+\mathrm{CNQX}$ + strychnine. Adding strychnine to the gabazine-APV-CNQX mixture completely but reversibly blocks the wave of propagating activity as well as the GDPs. ${ }^{* *} p<0.01 .{ }^{* * *} p<0.001$.

dropped to $62.6 \pm 4.3 \%$ of the control value in the presence of gabazine, but this reduction was not significant (Fig. 7A1,A5). When glutamatergic receptors were blocked by adding DL-APV $(200 \mu \mathrm{M})$ and CNQX $(20 \mu \mathrm{M})$ in the presence of gabazine, sGDPs depolarized the $\mathrm{MN}$ membrane potential to a value ranging from $-56 \mathrm{mV}$ to $-40 \mathrm{mV}(-44.4 \pm 0.72 \mathrm{mV} ; 21 \mathrm{sGDPs} ; N=5)$, which was significantly lower than the value observed in control conditions $(p<0.01)$ (Fig. 7A1,A3). The additional blockade of glutamate receptors with DL-APV-CNQX in the presence of gabazine completely prevented spontaneous action potentials during sGDPs $(N=5)$ (Fig. 7A1,A4) and significantly reduced the depolarizing area of the sGDP $(48.5 \pm 3.7 \%$ of control) (Fig. $7 A 1, A 5)$.

When DL-APV and CNQX solution was applied alone, we found that sGDPs reached significantly $(p<0.001)$ less depolarized values $(-32.6 \pm 0.34 \mathrm{mV}, 11 \mathrm{sGDPs}, N=3)$ compared with the control ( $-28.45 \pm 0.66 \mathrm{mV}, 15 \mathrm{sGDPs}, N=3$ ) (Fig. 7A2,A3). This lower depolarization was accompanied by a slight but nonsignificant reduction of the excitability because $47.2 \pm 26.5 \%$ of sGDPs evoked action potentials (16\%-100\% of sGDPs, depending on the cell tested, $0-1$ action potential), whereas $100 \%$ of control sGDPs evoked action potentials (1-3 action potentials) (Fig. 7A2,A4) $(N=3)$.
As shown in Figure 6, blocking both $\mathrm{GABA}_{\mathrm{A}} \mathrm{R}$ and glutamate receptor activation prevented GDPs from evoking action potentials, although sGDPs were not abolished. As theoretically predicted by our calculations, these data thereby suggest that glycine-evoked change in MN conductance, although minor, should be of significance in evoking sGDPs with respect to the high $\mathrm{R}_{\text {input }}$ of the embryonic MNs. Indeed, although the application of strychnine alone did not inhibit the SC activity (Scain et al., 2010), the residual sGDPs observed in the presence of gabazine-DL-APV-CNQX solution were completely abolished when strychnine $(3 \mu \mathrm{M})$ was added to the antagonist solution (Fig. $7 B)(N=4)$.

These results show that the GABA, glutamate, and glycine components of sGICs are partly redundant in generating sGICs, the amplitude of which is high enough to generate action potentials. They also indicate that the shunting effect in response to the large conductance changes during sGIC with respect to the low input conductance of MNs are likely to play important functions by stabilizing the level of depolarization of the MN membrane potential, which might make sGDPs more prone to generate action potentials. The shunting effect caused by the large increase in membrane conductance could also restrict frequent action potential firing, although $\mathrm{MN}$ action potential firing is more likely 
A1

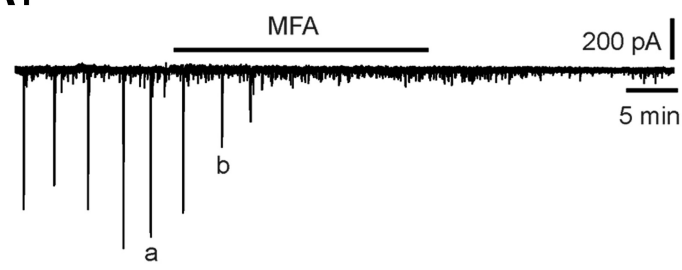

A2

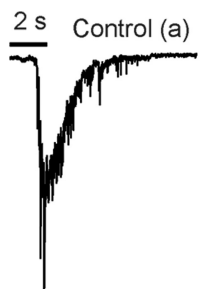

B1

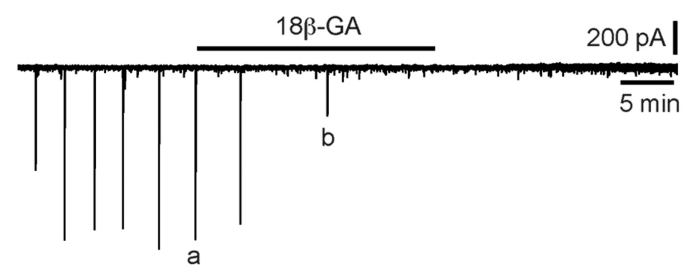

B2

$\mathbf{C}_{1}$

$\mathrm{C}_{2}$
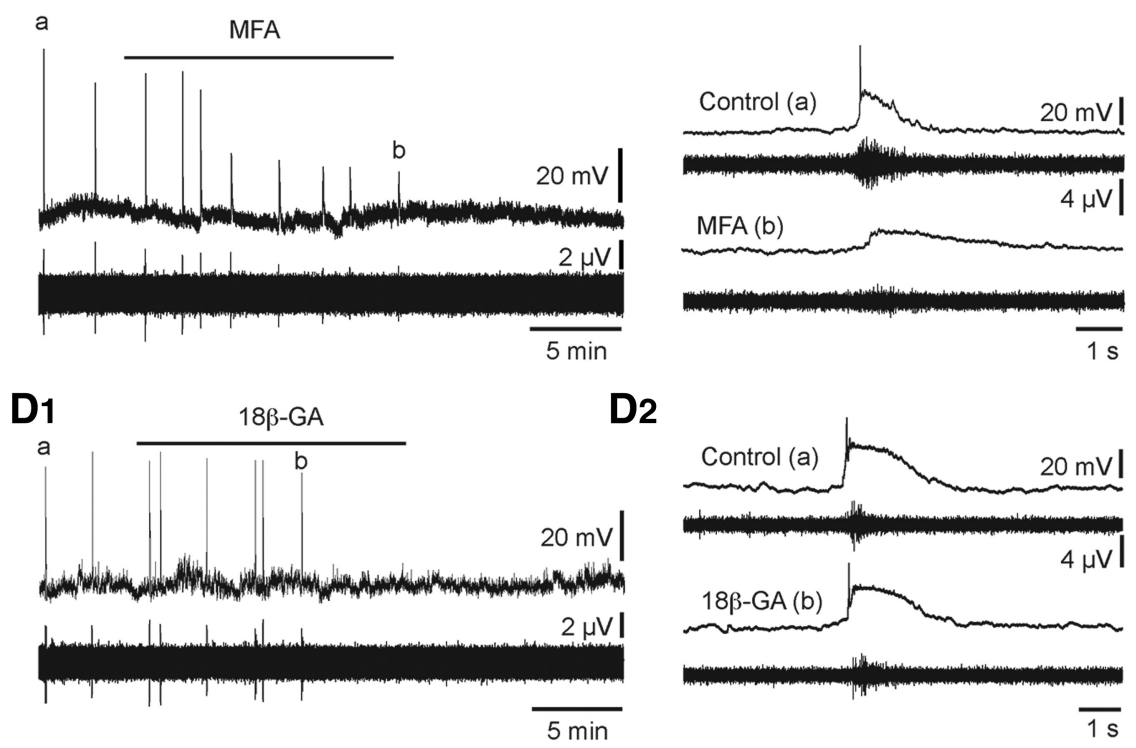

D2

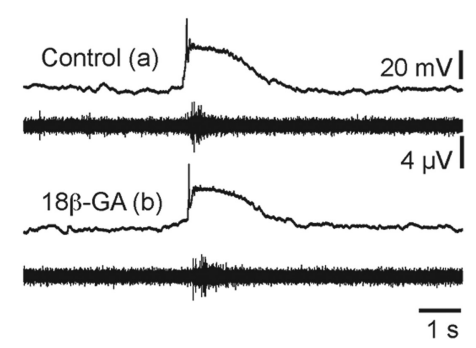

Figure 8. GAP junctions participate in the generation of $s \mathrm{GICs}$ and SGDPs. Application of the GAP junction blockers MFA (50 $\mu \mathrm{M})$ $(\boldsymbol{A})$ and $18 \beta$-GA $(50 \mu \mathrm{M})(\boldsymbol{B})$ fully blocks sGICs. $\boldsymbol{A}$, $\boldsymbol{B 1}$, Continuous recording of MN activity before and during MFA and $18 \beta$-GA application, respectively $\left(V_{\mathrm{h}}=-60 \mathrm{mV}\right)$. A2, B2, Examples of sGICs recorded in the presence or absence of MFA and 18 $\beta$-GA, respectively $\left(V_{h}=-60 \mathrm{mV}\right)$. C, D, Simultaneous extracellular recording of the SC spontaneous activity and patch-clamp currentclamp recording of sGDPs $\left(V_{m}=-60 \mathrm{mV}\right)$. Application of the GAP junction blockers MFA $(50 \mu \mathrm{m})(C)$ and $18 \beta-G A(D)$ fully blocks SGDPs. C1, D1, Continuous recording of MN activity before and during MFA and 18 $\beta$-GA application, respectively. C2, D2, Examples of SGDPs and extracellular recordings recorded in the presence or absence of MFA and 18 $\beta$-GA, respectively.

limited by the intrinsic activation properties of this neuron at this developmental stage (see above).

Role of GABA, glutamate, and glycine in the control of the SC network at the onset of synaptogenesis

We then determined to what extent the combination of antagonists could alter the SC network activity related to sGDP activity recorded in MNs by performing simultaneous current-clamp and extracellular recordings (Fig. 7). Our data showed that there was no significant difference in SC network activity in the presence of gabazine ( $p>0.1$ for all comparisons, $N=4$ ) (Fig. 7A1), the burst duration (control: $2.82 \pm 0.30 \mathrm{~s}$; gabazine: $2.99 \pm$ $0.24 \mathrm{~s}$ ), and the burst area (control: $732 \pm 126$ a.u.; gabazine: $830 \pm 163$ a.u.). Finally, gabazine did not affect the frequency of
7

MFA (b)

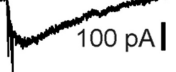

spontaneous activity (control period: $3.3 \pm 0.4 \mathrm{~min}$; gabazine: $3.5 \pm 0.2 \mathrm{~min}$ ).

When DL-APV and CNQX were applied alone, we found that the burst duration (control: $2.89 \pm 0.24 \mathrm{~s}$; APV-CNQX $2.92 \pm 0.14 \mathrm{~s}$ ), the burst area (control: $537 \pm 106$ a.u.; APV-CNQX: $531 \pm$ 117 a.u.), and the frequency (control period: $3.3 \pm 0.5 \mathrm{~min}$; APV-CNQX: $3.8 \pm$ $0.3 \mathrm{~min}$ ) were not significantly affected ( $p>0.1$ for all comparisons, $N=3$; Fig. 7A2).

Moreover, in the presence of gabazine plus DL-APV-CNQX, the burst duration $(2.81 \pm 0.26 \mathrm{~s})$ and area $(734 \pm 134$ a.u. $)$ and the frequency of spontaneous activity (control period: $3.3 \pm 0.4 \mathrm{~min}$; gabazineAPV-CNQX: $3.6 \pm 0.5 \mathrm{~min})$ were not significantly changed $(p>0.1)$ (Fig. 7A1). As observed for sGDPs recorded on $\mathrm{MNs}$, SC activity was abolished when strychnine was added to the DL-APV-CNQX and gabazine solution (Fig. 7B), indicating that the release of GABA, glutamate, and glycine may be redundant but contributes to the robust control of the local SC network activity.

sGIC and sGDP spontaneous activities require gap junction electrical coupling The results described above cannot rule out the possibility that mechanisms other than chemical transmission contribute to SC neuron synchronization as electrical coupling between neurons through gap junctions. Gap junction coupling is found in the spinal ventral zone from E11 (Bittman et al., 2004), and early spinal spontaneous activity is abolished at E12 by the gap junction inhibitors carbenoxolone and octanol (Hanson and Landmesser, 2003). To assess the contribution of gap junction to the generation of sGDPs and sGICs, we used 18- $\alpha$ glycyrrhetinic acid (18- $\alpha$-GA) and $18-\beta$ glycyrrhetinic acid (18- $\beta-\mathrm{GA})$ and the potent gap junction inhibitor meclofenamic acid (MFA) (see Materials and Methods). We first tested the effect of these gap junction inhibitors on sGIC activity. As shown in Figure $8 A, B$, MFA ( $50 \mu \mathrm{M}, N=6)$ and $18-\beta$-GA $(50 \mu \mathrm{M}, N=5)$ completely abolished the spontaneous GIC activity, whereas $18-\alpha$-GA had no effect (data not shown). We further investigated the effect of MFA and $18-\beta$-GA on SC network activity and sGDP activity. In the same manner, $\operatorname{MFA}(50 \mu \mathrm{M}, N=4)$ and $18-\beta-\mathrm{GA}(50 \mu \mathrm{M}, N=3)$ both completely inhibited sGDPs and SC global network activity, as shown in Figure $8 C, D$.

Because both 18- $\beta$-GA and $18-\alpha$-GA had identical side effects whereas $18-\beta-G A$ is highly effective only in blocking gap junctions (Guan et al., 2007), we can conclude that the inhibition of sGIC activity results from a block of gap junctions. MFA transiently increased the half-width of sGICs before the total inhibition of the activity (control: $0.6 \pm 0.1 \mathrm{~s}$; MFA: $4.1 \pm 0.7 \mathrm{~s} ; p<$ $0.01, N=6$ ) (Fig. 8A2), but this effect was not observed with 
18- $\beta$-GA. Accordingly, it is unclear whether the increase in sGIC duration observed in the presence of MFA resulted from a progressive loss of neuron synchronization or from side effects of this compound on other channels (see Materials and Methods).

\section{ACh release regulates sGIC activity on MNs}

Our observation that sGDPs are generated by simultaneous release of GABA, glutamate, and glycine onto MNs during spontaneous SC activity at E12.5 may appear inconsistent with previous studies reporting that MN firing and SC spontaneous activity strongly depend on $\mathrm{nAChR}$ activation at E12.5 (Hanson and Landmesser, 2003; Myers et al., 2005). To determine the prospective role of $\mathrm{nAChR}$ activation in shaping $\mathrm{MN}$ activity, we tested the effects of $\mathrm{nAChR}$ antagonists, mecamylamine $(50 \mu \mathrm{M})$ with D-turbocurarine $(10 \mu \mathrm{M})$ or $\mathrm{DH} \beta \mathrm{E}(5 \mu \mathrm{M})$, on spontaneous GIC activity at concentrations known to significantly alter the spontaneous embryonic SC activity (Hanson and Landmesser, 2003). $\mathrm{DH} \beta \mathrm{E}$ has a high affinity for rat $\alpha 4 \beta 2, \alpha 4 \beta 4$, and $\alpha 3 \beta 2$ receptor subtypes and a low affinity for $\alpha 3 \beta 4 \mathrm{nAChRs,} \mathrm{whereas} \mathrm{mecamyl-}$ amine and D-turbocurarine are nonselective inhibitors of nAChRs (Dwoskin and Crooks, 2001). Mecamylamine and D-turbocurarine application $(N=5)$ (Fig. 9A1,A2) or $\mathrm{DH} \beta \mathrm{E}$ application $(N=5)$ (Fig. $9 B 1, B 2)$ fully and reversibly blocked spontaneous GIC activity, which thus confirmed that nAChR endogenous activation is essential to spontaneous MN GIC activity at E12.5.

However, these results did not necessarily imply that ACh acts directly on MNs as it could act indirectly by regulating neurotransmitter release from INs onto MNs. To address this issue, we analyzed the $\mathrm{MN}$ response to the application of ACh. As shown in Figure $10 A 1-A 3$, a $5 \mathrm{~s}$ application of $100 \mu \mathrm{M}$ ACh evoked large inward currents with amplitude ranging from 79 to 755 pA ( $286.3 \pm 41.1 \mathrm{pA} ;=26)$. This current was generally composed of an initial transient phase characterized by large postsynaptic currents and a second phase characterized by a plateau and superimposed small-amplitude fast currents resembling postsynaptic currents. The amplitude of the ACh-evoked current was significantly decreased but not completely blocked after application of $5 \mu \mathrm{M} \mathrm{DH} \beta \mathrm{E}(32.1 \pm 4.8 \%$ decreased, $p<0.05 ; N=$ 6) (Fig. 10A1,A4). Adding the two nonselective nAChR antagonists mecamylamine $(50 \mu \mathrm{M})$ and D-turbocurarine $(10 \mu \mathrm{M})$ to the $\mathrm{DH} \beta \mathrm{E}$ solution resulted in a $95 \pm 1.1 \%$ inhibition of the total current $(N=8)(p<0.01)$ (Fig. 10A1,A4), indicating that both $\mathrm{DH} \beta \mathrm{E}$-sensitive nAChRs $(\alpha 4 \beta 2, \alpha 4 \beta 4, \alpha 3 \beta 2)$ (Dwoskin and Crooks, 2001) and $\mathrm{DH} \beta \mathrm{E}$-insensitive nAChRs were involved in the response evoked by ACh on MNs. However, the occurrence of many postsynaptic-like currents in response to ACh application could suggest that at least part of the response results from the activation of the IN network controlling MN activity. AChevoked currents were decreased by $72.6 \pm 3.5 \%(N=14)$ in the presence of gabazine $(p<0.01)$ (Fig. 10A2,A4), and the addition of $200 \mu \mathrm{M}$ DL-APV and $20 \mu \mathrm{M}$ CNQX to the gabazine solution resulted in a $91.4 \pm 2.6 \%(N=14)$ decrease of the total current evoked by the application of ACh $(p<0.01)$ (Fig. 10A3,A4). Interestingly, when $3 \mu \mathrm{M}$ strychnine was added to the gabazine/
DL-APV/CNQX solution, the current amplitude was further decreased to $6.3 \pm 2.4 \%$ of the control value $(N=6 ; p<0.01)$ (Fig. $10 A 3, A 4)$. These results thereby confirm that $\mathrm{nAChR}$ activation in E12.5 SC can evoke the activation of the SC IN network projecting on MNs, but they also suggest that MNs express very few functional nAChRs at the cell membrane. The absence of functional cholinergic inputs onto MNs at this stage was further confirmed by testing the effects of nAChR antagonists on GICs evoked by high $\mathrm{K}^{+}$application. Applications of $\mathrm{DH} \beta \mathrm{E}(5 \mu \mathrm{M})$ or mecamylamine $(50 \mu \mathrm{M})$ and D-turbocurarine $(10 \mu \mathrm{M})$ had no significant effect $(p>0.1)$ on the amplitude of eGICs (Fig. $9 B 1, B 2)$. In the presence of $\mathrm{DH} \beta \mathrm{E}(N=5)$, eGIC amplitude showed a nonsignificant $5.4 \pm 8.7 \%$ decrease. Likewise, eGIC amplitude was not significantly decreased $(2.4 \pm 4.1 \%$ decrease $)$ in the presence of mecamylamine plus D-turbocurarine $(N=5)$ (Fig. 10B1,B2). We therefore conclude that even a global depolarization of the SC network by high $\mathrm{K}^{+}$is unable to induce any significant cholinergic current in MNs.

The inhibition of SC network activity evoked by nAChR antagonists could result from a decrease in the excitability level of the INs projecting on MNs in the absence of ACh or from the suppression of an ACh-dependent generator controlling the activity pattern of the INs. To address these issues, we tested the ability of the SC network to evoke GDPs as a reflection of IN activity on MNs with a $7 \mathrm{~mm}$ extracellular $\mathrm{K}^{+}$solution in the presence of the broad-spectrum $\mathrm{nAChR}$ antagonists mecamylamine and D-turbocurarine. As shown in Figure 11A1, A2, depolarizing the SC network using $7 \mathrm{~mm}$ extracellular $\mathrm{K}^{+}$solution restored sGIC activity in the presence of the nAChR antagonists. The frequency of sGICs in these conditions was three times higher $(0.94 \pm 0.18 \mathrm{sGICs} / \mathrm{min} ; N=5)$ than that observed in control conditions, whereas these $\mathrm{nAChR}$ antagonist-resistant sGICs completely disappeared in response to simultaneous applications of gabazine, DL-APV, and CNQX $(N=5)$ (Fig. 11A1). Extracellular $\mathrm{K}^{+}$concentration $<7 \mathrm{~mm}$ did not restore sGIC activity $(N=5$; data not shown). GICs observed in the presence of $\mathrm{nAChR}$ antagonists and an elevated extracellular $\mathrm{K}^{+}$concentration had amplitudes of $41.7 \pm 12.3 \%(N=5)$ compared with GIC 


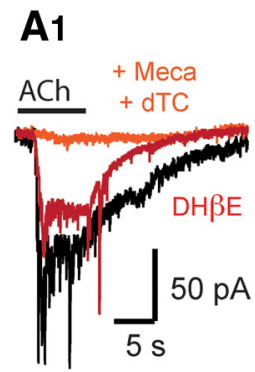

A2

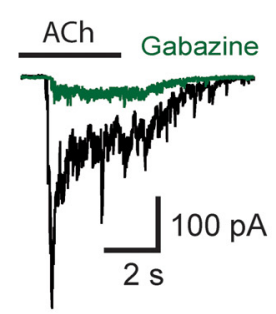

A3

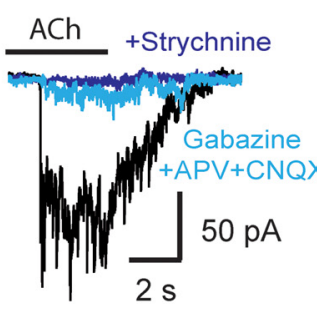

A4

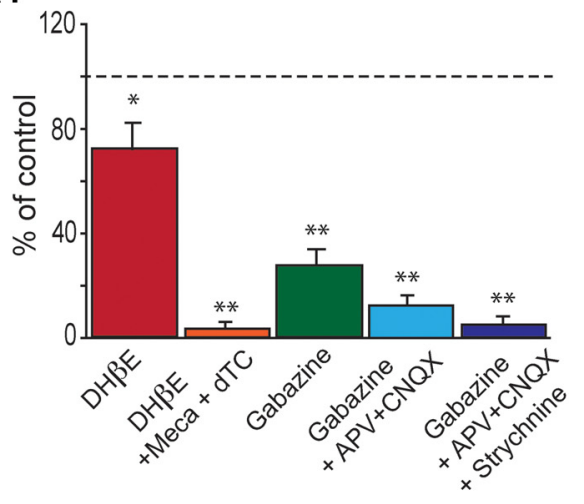

B1

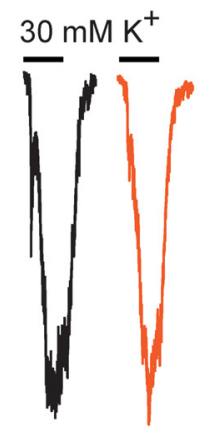

Meca+dTC

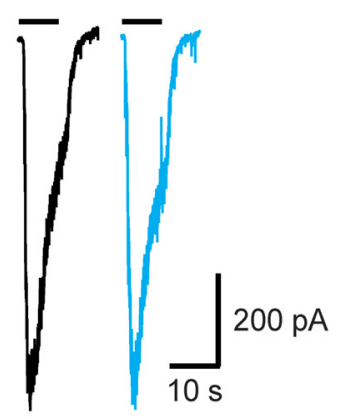

$\mathrm{DH} \beta \mathrm{E}$
B2

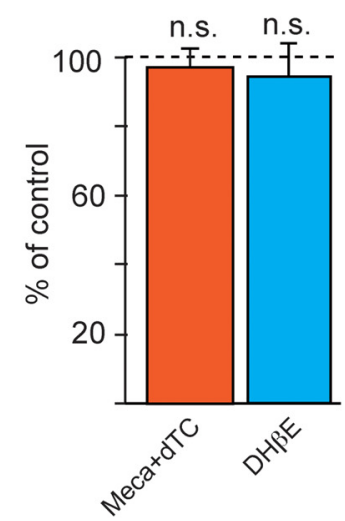

Figure 10. $\mathrm{nAChR}$ activation evoked GABA, glutamate, and glycine release. A1, Application of $100 \mu \mathrm{m} A C h$ in control conditions (black), in the presence of $5 \mu \mathrm{m}$ DH $\beta \mathrm{E}$ (red) or in the presence of $50 \mu \mathrm{m}$ mecamylamine plus $10 \mu \mathrm{m} \mathrm{dTC} \mathrm{(orange).} \mathrm{A2,} \mathrm{Application} \mathrm{of} 100 \mu \mathrm{m}$ ACh in control conditions (black), in the presence of $3 \mu \mathrm{m}$ of gabazine (green). A3, Application of $100 \mu \mathrm{m}$ ACh in control conditions (black), in the presence of gabazine $+200 \mu \mathrm{m} \mathrm{DL}-A P V$ and $20 \mu \mathrm{m}$ CNQX (light blue) and in the presence of $3 \mu \mathrm{m}$ of gabazine $+\mathrm{DL}-\mathrm{APV}, \mathrm{CNQX}$, and strychnine (3 $\mu \mathrm{m}$ ) (dark blue). A4, Mean values of $\mathrm{ACh}$ amplitude evoke inward current in the presence of the different antagonists. $\mathrm{V}_{\mathrm{h}}=-60 \mathrm{mV}$. B1, Example of inward currents evoked by the application of high $\mathrm{K}^{+}$solutions ( $30 \mathrm{~mm}$ ) in control conditions and in the presence of nAChR antagonists mecamylamine (50 $\mu \mathrm{m})+\mathrm{D}$-turbocurarine (10 $\mu \mathrm{m})$ (red) or DH $\beta \mathrm{E}$ (5 $\mu \mathrm{m})$ (blue). B2, eGICs are insensitive to nAChR antagonists. $\mathrm{V}_{\mathrm{h}}$ $=-60 \mathrm{mV} .{ }^{*} p<0.05 ;{ }^{* *} p<0.01$. n.s., Not significant.

amplitude in control conditions. These results indicate that, although ACh release was required for the spontaneous occurrence of sGICs, it was unlikely to be involved in mechanisms shaping the pattern of sGIC activity. But they also indicate that nAChR activation plays a central role in the control of sGIC amplitude. This could indicate a modulation by nAChRs of the amount of neurotransmitter release by INs projecting on MNs.

ACh may directly regulate the release of neurotransmitter from synaptic terminals. We thus analyzed the pharmacological nature of the currents evoked on MNs by the application of ACh in the absence of any SC network activity abolished by TTX $(1 \mu \mathrm{M}$ TTX). In the presence of TTX (Fig. 11B), an application of 100 $\mu \mathrm{M}$ ACh was still able to generate a current $(34.6 \pm 2.7 \%$ of control; $N=10$ ), which was nearly completely blocked by $\mathrm{DH} \beta \mathrm{E}$ $(84.2 \pm 3.3 \%$ decreased; $N=9 ; p<0.01)$ (Fig. 11B1), thus indicating that this SC activity-independent current evoked by $\mathrm{ACh}$ was mainly the result of the activation of $\mathrm{DH} \beta \mathrm{E}$-sensitive nAChRs. This TTX-resistant current was also fully blocked by 50 $\mu \mathrm{M}$ mecamylamine added to $10 \mu \mathrm{M} \mathrm{D}$-turbocurarine $(N=5$, data not shown). More importantly, this TTX-resistant component of ACh-evoked response was also characterized by the occurrence of two types of small fast events with a time course similar to postsynaptic currents that are likely miniature postsynaptic currents (Fig. 11B1). This result indicated that ACh could act on nAChRs expressed by presynaptic nerve terminals to directly induce a synaptic release of neurotransmitter. Slow miniature postsynaptic ACh-evoked currents with a half-amplitude duration of $27.7 \pm 2.1 \mathrm{~ms}$ and a mean amplitude of $34.1 \pm 11.2 \mathrm{pA}(N=14)$ were observed in $100 \%$ of the recorded MNs in the presence of TTX (Figs. 11B1 and 11B2). These slow miniature postsynaptic currents were blocked by $3 \mu \mathrm{m}$ gabazine. In the presence of gabazine, the global amplitude of the response evoked by ACh was significantly $(p<0.01)$ decreased $(66.6 \pm 6 \% ; N=7)$ (Fig. 11B2). In the presence of TTX and gabazine (Fig. 11B2,B3), fast miniature postsynaptic events could still be observed in response to $\mathrm{ACh}$ in $70 \%$ of the recorded $\mathrm{MNs}(N=12)$. These miniature postsynaptic currents had a fast time course (half-amplitude duration $=0.9 \pm 0.2 \mathrm{~ms} ; N=5)$ and a mean amplitude of $25.9 \pm 1.8$ pA $(N=5)$. These fast miniature postsynaptic currents were fully blocked in the presence of CNQX $(20 \mu \mathrm{M})+$ DL-APV $(200 \mu \mathrm{M})$ (Fig. $11 B 3 ; N=9$ ), suggesting that they are all glutamatergic miniature postsynaptic currents. Together, our results therefore demonstrate that ACh may directly regulate GABA and glutamate release from synaptic terminals through the activation of $\mathrm{DH} \beta$ E-sensitive presynaptic nAChRs in the embryonic E12.5 SC.

\section{Discussion}

Our study demonstrates, for the first time, that IN networkdriven GDPs control the activity of MNs at the onset of synaptogenesis in the embryonic SC. GDPs were mediated by the release 
of GABA, glutamate, and glycine. Although $\mathrm{ACh}$ is essential for the generation of spontaneous SC activity (Hanson and Landmesser, 2003; Myers et al., 2005), we show that ACh is unable to activate MNs directly, but it is likely to influence MN activity via the activation of INs and a direct presynaptic regulation of GABA and glutamate release.

\section{GDPs depend on the release of GABA, glutamate, and glycine at the onset of synaptogenesis}

GDPs and their current counterparts GICs of embryonic MNs at E12.5 partially share properties with cortical and hippocampal GDPs and are closely related to GABAergic GDPs observed in the hippocampus and the cortex at postnatal stages (Ben-Ari et al., 1989; Sipilä et al., 2005; Allène et al., 2008). These findings suggest that GDP is a common mechanism accounting for synchronized neuronal assembly during early nervous system development.

It is known that neurotransmitter release controls the SC activity at E12.5 in mouse embryo (Hanson and Landmesser, 2003), but we provide evidence that they can directly control MN activity though GDPs. GDPs are evoked by the activation of $\mathrm{GABA}_{\mathrm{A}}$, glycine, and glutamate receptors on $\mathrm{MNs}$ through a vesicular-dependent release of the neurotransmitters. Accordingly, it is likely that, at this age, MNs receive direct GABAergic, glycinergic, and glutamatergic inputs. Interestingly, the GABA current is the major component of GICs, although it is not crucially required to generate GDPs. We found little effect of the $G_{A B A} R$ antagonist gabazine on the frequency of GICs, or on GDP and SC network activity, which contrasts with previous work showing a twofold decrease in SC activity in the presence of different $G_{A B A} R$ antagonists (bicuculline and picrotoxin) (Hanson and Landmesser, 2003). The presence of a glycine component in GICs, although minor, suggests that vesicular voltage-dependent glycine release already occurs in E12.5 SC. The low sensitivity of the glycine GIC component for strychnine may be surprising, but we noted the relatively low affinity of embryonic GlyRs for strychnine previously shown in the embryonic neocortex (Flint et al., 1998). Paracrine glycine release from radial glial cells is known to regulate the frequency of embryonic SC activity (Scain et al., 2010), but vesicular glycine or GABA was unlikely to be released from radial glial cells because we detected no VIAAT expression in these progenitors (Scain et al., 2010). Accordingly, our results suggest that few INs release glycine at E12.5.

The occurrence of glutamatergic postsynaptic currents in addition to GABAergic postsynaptic currents at E12.5 indicates that both synaptic systems become functional at the onset of synaptogenesis in the embryonic SC, in contrast to what has previously been suggested. Based on the analysis of the frequency of the rhythm of SC activity using extracellular recordings, previous publications have proposed a delayed occurrence of the glutamatergic synaptic network compared with the GABAergic and the cholinergic synaptic network during early SC maturation (Hanson and Landmesser, 2003; Myers et al., 2005). This apparent contradiction can be explained by the fact that, although glutamatergic synaptic inputs on MNs are already functional at E12.5, their blockade alone is not sufficient to significantly modify MN firing as measured previously on ventral roots. Interestingly, we observed that GABA/glycine receptor activation and glutamate receptor activation are not simultaneous but partly sequential during a GIC, although glutamate release was not required for GABAergic IN activation because sGICs or sGDPs still occurred in the presence of glutamate receptor antagonists. For similar reasons, GABA release was not required for the activation of glutamatergic INs, suggesting that synaptic interconnections between these INs were not essential for their activation. The reason for the delayed occurrence of GABA receptor activation during a GIC compared with glutamate receptor activation remains unclear. This could result from a different location and/or a better synchronization of glutamate INs or from GAP-junction coupling between glutamate INs.

Because of the high $\mathrm{R}_{\text {input }}$ of $\mathrm{MNs}$, small currents are likely to be sufficient to evoke MN activity. Consistently, the release of GABA, glutamate, and glycine evoking large GICs is redundant in generating GDPs controlling MN spike firing. These currents result from the activation of a large number of receptor channels evoking a large increase in membrane conductance, which causes a shunting effect. This shunting effect could restrict frequent firing in MNs. But it should be pointed out that MNs cannot sustain continuous spike firing at this age because of their immature intrinsic electrical properties. At E12.5, this shunting effect rather limits and stabilizes the GDP amplitude as predicted by our calculations.

Thus, participation of GABAergic, glutamatergic, and glycinergic conductances in GDPs, and their respective importance, provides a robust mechanism to control $\mathrm{MN}$ activity as at later developmental stages in the chick embryo (Chub and O'Donovan, 1998). This complexity contributes to normal MN development because motor axon guidance and $\mathrm{MN}$ pool forma- 
tion are degraded by pharmacologically induced changes in SC activity patterns (eg, chick embryonic SC) (Hanson et al., 2008).

\section{ACh has a crucial role in the occurrence of SC activity via its regulation of neurotransmitter release from INs}

As previously shown, $\mathrm{ACh}$ release is required for the occurrence of SC network activity. Blocking nAChR clearly inhibits spontaneous GIC occurrence on MNs (present study) and prevents the burst propagation along the cord (Hanson and Landmesser, 2003). Furthermore, no MN spontaneous activity could be detected in E12.5 $\mathrm{CAT}^{-1-}$ mouse embryos (Myers et al., 2005). But ACh release is unlikely to control GIC rhythmicity pattern because recurrent GICs were partially restored in the presence of $\mathrm{nAChR}$ antagonists when external $\mathrm{K}^{+}$concentration was increased. Accordingly, neurons releasing ACh are unlikely to act as pattern generators as the pattern of the embryonic SC activity must be controlled by other mechanisms, as previously suggested at later developmental stages in the chick embryo (for review, see Momose-Sato and Sato, 2013). Because there is no evidence for the presence of functional AChRs on MNs at E12.5, the main function of ACh release must be the control of the activity of SC INs responsible for the GDPs on MNs.

ACh tends to have complex effects on INs as we show that ACh promotes IN activity by acting on $\mathrm{DH} \beta \mathrm{E}$-insensitive nAChRs expressed by INs and likely regulates GABA and glutamate synaptic release by acting on $\mathrm{DH} \beta \mathrm{E}$-sensitive presynaptic nAChRs. However, we cannot completely exclude that INs also express few postsynaptic $\mathrm{DH} \beta \mathrm{E}$-sensitive nAChRs. To our knowledge, functional presynaptic $\mathrm{DH} \beta \mathrm{E}$-sensitive nAChRs located on both glutamatergic and GABAergic terminals have not yet been described in the ventral SC or at such an early developmental stage. In the dorsal horn of the adult SC, ACh was shown to increase glycinergic miniature inhibitory synaptic events (Kiyosawa et al., 2001) in a way similar to that for dual GABA/glycine release in the substantia gelatinosa (Takeda et al., 2003). Conversely, all functional presynaptic nAChRs, with the exception of those including the $\alpha 7$ subunit, which are located on both GABAergic and glutamatergic presynaptic terminals, have been described in various brain areas (Alkondon and Albuquerque, 2002; Liu et al., 2007; Albuquerque et al., 2009; Tang et al., 2011; Garduño et al., 2012).

\section{Neuronal interactions in the embryonic SC at the onset of synaptogenesis}

It has previously been proposed that MNs are spontaneously active at the onset of synaptogenesis and that they control the pattern of early SC activity (Hanson and Landmesser, 2003; Myers et al., 2005). The SC activity at E12.5 is triggered by a propagating wave arising from the neuronal network of different segments of the SC at E12.5 (Momose-Sato and Sato, 2013). At E12.5, a mixed pattern of wave initiation was observed, with the activity appearing either in the cervical cord or in the lumbosacral cord (Momose-Sato and Sato, 2013). Because MNs cannot sustain continuous spike firing at E12.5 and action potentials were evoked in MNs by GDP only, it is difficult to argue that MNs are the only orchestra director of the SC network at E12.5. However, according to the high $\mathrm{R}_{\text {input }}$ of $\mathrm{MNs}$, few currents can evoke large membrane potential fluctuations that could evoke calcium influx and in turn ACh release. Because of the high $\mathrm{R}_{\text {input }}$ of immature neurons and electrical coupling, the activation of a few nAChRs could suffice to activate groups of INs within an SC segment and to promote neurotransmitter release from GABAergic and glutamatergic terminals. In turn, such a neurotransmitter release will evoke MN depolarization, thus allowing the increase in ACh re- lease, which will recruit more INs and allow massive neurotransmitter release underlying GDPs onto MNs with positive feedback. As discussed above, ACh release is unlikely to synchronize MNs directly. In this scenario, ACh regulates the excitability level of INs and the neurotransmitter release from IN terminals likely through the activation of presynaptic nAChRs.

\section{References}

Albuquerque EX, Pereira EF, Alkondon M, Rogers SW (2009) Mammalian nicotinic acetylcholine receptors: from structure to function. Physiol Rev 89:73-120. CrossRef Medline

Alkondon M, Albuquerque EX (2002) A non-alpha7 nicotinic acetylcholine receptor modulates excitatory input to hippocampal CA1 interneurons. J Neurophysiol 87:1651-1654. Medline

Allène C, Cossart R (2010) Early NMDA receptor-driven waves of activity in the developing neocortex: physiological or pathological network oscillations? J Physiol 588:83-91. CrossRef Medline

Allène C, Cattani A, Ackman JB, Bonifazi P, Aniksztejn L, Ben-Ari Y, Cossart R (2008) Sequential generation of two distinct synapse-driven network patterns in developing neocortex. J Neurosci 28:12851-12863. CrossRef Medline

Alvarez FJ, Villalba RM, Zerda R, Schneider SP (2004) Vesicular glutamate transporters in the spinal cord, with special reference to sensory primary afferent synapses. J Comp Neurol 472:257-280. CrossRef Medline

Ben-Ari Y, Cherubini E, Corradetti R, Gaiarsa JL (1989) Giant synaptic potentials in immature rat CA3 hippocampal neurones. J Physiol 416:303325. Medline

Bittman KS, Panzer JA, Balice-Gordon RJ (2004) Patterns of cell-cell coupling in embryonic spinal cord studied via ballistic delivery of gap-junctionpermeable dyes. J Comp Neurol 477:273-285. CrossRef Medline

Blankenship AG, Feller MB (2010) Mechanisms underlying spontaneous patterned activity in developing neural circuits. Nat Rev Neurosci 11:1829. CrossRef Medline

Borgius L, Restrepo CE, Leao RN, Saleh N, Kiehn O (2010) A transgenic mouse line for molecular genetic analysis of excitatory glutamatergic neurons. Mol Cell Neurosci 45:245-257. CrossRef Medline

Branchereau P, Chapron J, Meyrand P (2002) Descending 5-hydroxytryptamine raphe inputs repress the expression of serotonergic neurons and slow the maturation of inhibitory systems in mouse embryonic spinal cord. J Neurosci 22: 2598-2606. Medline

Bury LA, Sabo SL (2011) Coordinated trafficking of synaptic vesicle and active zone proteins prior to synapse formation. Neural Dev 6:24. CrossRef Medline

Chaudhry FA, Reimer RJ, Bellocchio EE, Danbolt NC, Osen KK, Edwards RH, Storm-Mathisen J (1998) The vesicular GABA transporter, VGAT, localizes to synaptic vesicles in sets of glycinergic as well as GABAergic neurons. J Neurosci 18:9733-9750. Medline

Chub N, O’Donovan MJ (1998) Blockade and recovery of spontaneous rhythmic activity after application of neurotransmitter antagonists to spinal networks of the chick embryo. J Neurosci 18:294-306. Medline

Corlew R, Bosma MM, Moody WJ (2004) Spontaneous, synchronous electrical activity in neonatal mouse cortical neurones. J Physiol 560:377-390. CrossRef Medline

Cousin MA, Nicholls DG (1997) Synaptic vesicle recycling in cultured cerebellar granule cells: role of vesicular acidification and refilling. J Neurochem 69:1927-1935. CrossRef Medline

Delpy A, Allain AE, Meyrand P, Branchereau P (2008) NKCC1 cotransporter inactivation underlies embryonic development of chloride-mediated inhibition in mouse spinal motoneuron. J Physiol 586:1059-1075. Medline

Demarque M, Represa A, Becq H, Khalilov I, Ben-Ari Y, Aniksztejn L (2002) Paracrine intercellular communication by $\mathrm{a} \mathrm{Ca}^{2+}$ - and SNAREindependent release of GABA and glutamate prior to synapse formation. Neuron 36:1051-1061. CrossRef Medline

Dumoulin A, Rostaing P, Bedet C, Lévi S, Isambert MF, Henry JP, Triller A, Gasnier B (1999) Presence of the vesicular inhibitory amino acid transporter in GABAergic and glycinergic synaptic terminal boutons. J Cell Sci 112:811-823. Medline

Dwoskin LP, Crooks PA (2001) Competitive neuronal nicotinic receptor antagonists: a new direction for drug discovery. J Pharmacol Exp Ther 298:395-402. Medline

Flint AC, Liu X, Kriegstein AR (1998) Nonsynaptic glycine receptor activa- 
tion during early neocortical development. Neuron 20:43-53. CrossRef Medline

Gao BX, Ziskind-Conhaim L (1998) Development of ionic currents underlying changes in action potential waveforms in rat spinal motoneurons. J Neurophysiol 80:3047-3061. Medline

Garaschuk O, Hanse E, Konnerth A (1998) Developmental profile and synaptic origin of early network oscillations in the CA1 region of rat neonatal hippocampus. J Physiol 507:219-236. CrossRef Medline

Garaschuk O, Linn J, Eilers J, Konnerth A (2000) Large-scale oscillatory calcium waves in the immature cortex. Nat Neurosci 3:452-459. CrossRef Medline

Garduño J, Galindo-Charles L, Jiménez-Rodriguez J, Galarraga E, Tapia D, Mihailescu S, Hernandez-Lopez S (2012) Presynaptic alpha4beta2 nicotinic acetylcholine receptors increase glutamate release and serotonin neuron excitability in the dorsal raphe nucleus. J Neurosci 32:1514815157. CrossRef Medline

Giaume C, Theis M (2010) Pharmacological and genetic approaches to study connexin-mediated channels in glial cells of the central nervous system. Brain Res Rev 63:160-176. CrossRef Medline

Gonzalez-Islas C, Wenner P (2006) Spontaneous network activity in the embryonic spinal cord regulates AMPAergic and GABAergic synaptic strength. Neuron 49:563-575. CrossRef Medline

Guan BC, Si JQ, Jiang ZG (2007) Blockade of gap junction coupling by glycyrrhetinic acids in guinea pig cochlear artery: a whole-cell voltage- and current-clamp study. Br J Pharmacol 151:1049-1060. CrossRef Medline

Gust J, Wright JJ, Pratt EB, Bosma MM (2003) Development of synchronized activity of cranial motor neurons in the segmented embryonic mouse hindbrain. J Physiol 550:123-133. CrossRef Medline

Hanson MG, Landmesser LT (2003) Characterization of the circuits that generate spontaneous episodes of activity in the early embryonic mouse spinal cord. J Neurosci 23:587-600. Medline

Hanson MG, Milner LD, Landmesser LT (2008) Spontaneous rhythmic activity in early chick spinal cord influences distinct motor axon pathfinding decisions. Brain Res Rev 57:77-85. CrossRef Medline

Herzog E, Bellenchi GC, Gras C, Bernard V, Ravassard P, Bedet C, Gasnier B, Giros B, El Mestikawy S (2001) The existence of a second vesicular glutamate transporter specifies subpopulations of glutamatergic neurons. J Neurosci 21:RC181. Medline

Juszczak GR, Swiergiel AH (2009) Properties of gap junction blockers and their behavioural, cognitive and electrophysiological effects: animal and human studies. Prog Neuropsychopharmacol Biol Psychiatry 33:181198. CrossRef Medline

Kaneko T, Fujiyama F (2002) Complementary distribution of vesicular glutamate transporters in the central nervous system. Neurosci Res 42:243250. CrossRef Medline

Kiyosawa A, Katsurabayashi S, Akaike N, Pang ZP, Akaike N (2001) Nicotine facilitates glycine release in the rat spinal dorsal horn. J Physiol 536: 101-110. CrossRef Medline

Landmesser LT, O’Donovan MJ (1984) Activation patterns of embryonic chick hind limb muscles recorded in ovo and in an isolated spinal cord preparation. J Physiol 347:189-204. Medline

Li P, Slaughter M (2007) Glycine receptor subunit composition alters the action of GABA antagonists. Vis Neurosci 24:513-521. CrossRef Medline

Liu Z, Otsu Y, Vasuta C, Nawa H, Murphy TH (2007) Action-potentialindependent GABAergic tone mediated by nicotinic stimulation of immature striatal miniature synaptic transmission. J Neurophysiol 98:581-593. CrossRef Medline

Marder E, Rehm KJ (2005) Development of central pattern generating circuits. Curr Opin Neurobiol 15:86-93. CrossRef Medline

Mohajerani MH, Cherubini E (2006) Role of giant depolarizing potentials in shaping synaptic currents in the developing hippocampus. Crit Rev Neurobiol 18:13-23. CrossRef Medline

Momose-Sato Y, Sato K (2013) Optical imaging of the spontaneous depolarization wave in the mouse embryo: origins and pharmacological nature. Ann N Y Acad Sci 1279:60-70. CrossRef Medline

Moody WJ, Bosma MM (2005) Ion channel development, spontaneous activity, and activity-dependent development in nerve and muscle cells. Physiol Rev 85:883-941. CrossRef Medline

Myers CP, Lewcock JW, Hanson MG, Gosgnach S, Aimone JB, Gage FH, Lee KF, Landmesser LT, Pfaff SL (2005) Cholinergic input is required during embryonic development to mediate proper assembly of spinal locomotor circuits. Neuron 46:37-49. CrossRef Medline

Rigato C, Buckinx R, Le-Corronc H, Rigo JM, Legendre P (2011) Pattern of invasion of the embryonic mouse spinal cord by microglial cells at the time of the onset of functional neuronal networks. Glia 59:675-695. CrossRef Medline

Rockhill W, Kirkman JL, Bosma MM (2009) Spontaneous activity in the developing mouse midbrain driven by an external pacemaker. Dev Neurobiol 69:689-704. CrossRef Medline

Sagné C, El Mestikawy S, Isambert MF, Hamon M, Henry JP, Giros B, Gasnier B (1997) Cloning of a functional vesicular GABA and glycine transporter by screening of genome databases. FEBS Lett 417:177-183. CrossRef Medline

Scain AL, Le Corronc H, Allain AE, Muller E, Rigo JM, Meyrand P, Branchereau P, Legendre P (2010) Glycine release from radial cells modulates the spontaneous activity and its propagation during early spinal cord development. J Neurosci 30:390-403. CrossRef Medline

Siksou L, Silm K, Biesemann C, Nehring RB, Wojcik SM, Triller A, El Mestikawy S, Marty S, Herzog E (2013) A role for vesicular glutamate transporter 1 in synaptic vesicle clustering and mobility. Eur J Neurosci 37: 1631-1642. CrossRef Medline

Sipilä ST, Huttu K, Soltesz I, Voipio J, Kaila K (2005) Depolarizing GABA acts on intrinsically bursting pyramidal neurons to drive giant depolarizing potentials in the immature hippocampus. J Neurosci 25:5280-5289. CrossRef Medline

Spitzer NC (2006) Electrical activity in early neuronal development. Nature 444:707-712. CrossRef Medline

Takamori S, Rhee JS, Rosenmund C, Jahn R (2000) Identification of a vesicular glutamate transporter that defines a glutamatergic phenotype in neurons. Nature 407:189-194. CrossRef Medline

Takeda D, Nakatsuka T, Papke R, Gu JG (2003) Modulation of inhibitory synaptic activity by a non-alpha4beta2, non-alpha7 subtype of nicotinic receptors in the substantia gelatinosa of adult rat spinal cord. Pain 101: 13-23. CrossRef Medline

Tang AH, Karson MA, Nagode DA, McIntosh JM, Uebele VN, Renger JJ, Klugmann M, Milner TA, Alger BE (2011) Nerve terminal nicotinic acetylcholine receptors initiate quantal GABA release from perisomatic interneurons by activating axonal T-type $(\mathrm{Cav} 3) \mathrm{Ca}(2)(+)$ channels and $\mathrm{Ca}(2)(+)$ release from stores. J Neurosci 31:13546-13561. CrossRef Medline

Vaughn JE, Sims T, Nakashima M (1977) A comparison of the early development of axodendritic and axosomatic synapses upon embryonic mouse spinal motor neurons. J Comp Neurol 175:79-100. CrossRef Medline

Watt AJ, Cuntz H, Mori M, Nusser Z, Sjöström PJ, Häusser M (2009) Traveling waves in developing cerebellar cortex mediated by asymmetrical Purkinje cell connectivity. Nat Neurosci 12:463-473. CrossRef Medline

Wichterle H, Lieberam I, Porter JA, Jessell TM (2002) Directed differentiation of embryonic stem cells into motor neurons. Cell 110:385-397. CrossRef Medline 